\title{
Mechanisms underlying overdrive suppression and overdrive excitation in guinea pig sino-atrial node
}

\author{
Adam T. Graziani \& Mario Vassalle* \\ Department of Physiology and Pharmacology, State University of New York, Downstate Medical Center, 450 \\ Clarkson Avenue, Box 31, Brooklyn, 11203, NY, USA
}

Received 20 January 2006; accepted 18 April 2006

(C) 2006 National Science Council, Taipei

Key words: sino-atrial node, overdrive suppression, overdrive excitation, force, rate, diastolic oscillations, potassium, calcium, nickel, cesium, lidocaine, tetrodotoxin

\begin{abstract}
Summary
The hypothesis that the pause that follows overdrive of the sino-atrial node (SAN) might be the net result of overdrive excitation and overdrive suppression was tested by studying rate and force patterns induced by overdrive in isolated guinea pig SAN superfused in vitro. In Tyrode solution, the pause is short and changes but little with longer or faster drives. In high $\left[\mathrm{K}^{+}\right]_{\mathrm{o}}$ solution, longer overdrives increase force percent-wise more than in Tyrode solution, shorten the pause and are followed by greater rate and force. When the SAN (quiescent in high $\left[\mathrm{K}^{+}\right]_{\mathrm{o}}$ ) is driven at $6 / \mathrm{min}$, faster overdrives are followed by stronger, slowly decreasing contractions. Alternating $10 \mathrm{~s}$ drives with $10 \mathrm{~s}$ pauses have little effect on force and rate in Tyrode solution, but progressively increase force and rate in high $\left[\mathrm{K}^{+}\right]_{\mathrm{o}}$. Cesium has effects similar to high $\left[\mathrm{K}^{+}\right]_{\mathrm{o}}$. High $\left[\mathrm{Ca}^{2+}\right]_{\mathrm{o}}$ increases force and in high $\left[\mathrm{K}^{+}\right]_{\mathrm{o}}$ increases the rate as well as it shortens the pause, whereas $\mathrm{Ni}^{2+}$ decreases force as well as rate and lengthens the pause. Barium dissociates the effects on force and rate. Lidocaine and tetrodotoxin decrease rate and force, and increase the pause duration. In overdrive excitation, the increase in rate is associated with an enhancement of diastolic voltage oscillations. It is concluded that in SAN the prevalence of $\mathrm{Ca}^{2+}$ load leads to overdrive excitation whereas the prevalence of $\mathrm{Na}^{+}$load leads to overdrive suppression. In Tyrode solution, the pause after drive appears to be the net result of these two different mechanisms.
\end{abstract}

Abbreviations: AP - action potential; MDP - maximum diastolic potential; DD - diastolic depolarization; $\mathrm{R}$ - control rate (prior to drive); $\mathrm{F}$ - control contractile force; $\mathrm{DF}_{1}$ - force of first driven beat; $\mathrm{DF}_{2}$ - force of last driven beat; pause - time interval between the last driven beat and the first spontaneous beat; $\mathrm{PDF}_{1}-$ force of the first beat after the pause; $\mathrm{PDR}_{1}$ - rate immediately after the pause; $\mathrm{PDR}_{2}$ - late (10-15 s) postdrive rate; $\mathrm{PDF}_{2}$ - late (10-15 s) post-drive force (see Figure 1); $\mathrm{SR}$ - sarcoplasmic reticulum; $g_{\mathrm{K}}-\mathrm{K}^{+}$ conductance; $a_{\mathrm{Na}}^{\mathrm{i}}-$ intracellular $\mathrm{Na}^{+}$activity; TTX - tetrodotoxin; $\mathrm{NCX}-\mathrm{Na}^{+}-\mathrm{Ca}^{2+}$ exchange current

\section{Introduction}

An increase in rate of sino-atrial node (SAN) often occurs under normal and abnormal conditions. It entails an enhanced ion exchange between extraand intra-cellular environments, since the number

*To whom correspondence should be addressed. Fax: + 718270-3103; E-mail: mario.vassalle@ downstate.edu of action potentials increases in the unit of time. Indeed, a faster rate increases intracellular $\mathrm{Na}^{+}$ $[1,2]$ and $\mathrm{Ca}^{2+}$ [e.g., 3-5] in cardiac tissues, including the SAN [6]. Overdrive increases contractile force as well [e.g., 5, 7].

Overdrive of cardiac pacemakers is followed by a temporary suppression of discharge which is much shorter in the sino-atrial node $[8,9]$ than in Purkinje fibers [10]. The reason for this difference 
has not been determined. It might be related to the fact that morphologically and functionally the SAN is not a homogenous structure, since slow responses are recorded in dominant pacemaker cells and fast responses in subsidiary pacemaker cells [11-13]. The upstroke of dominant action potentials is caused by $\mathrm{Ca}^{2+}$ entry through the slow $\mathrm{Ca}^{2+}$ channel [11] whereas that of subsidiary pacemakers is mostly caused by $\mathrm{Na}^{+}$entry through the fast $\mathrm{Na}^{+}$channel [12]. Therefore, an increase in rate is expected to predominantly increase $\mathrm{Ca}^{2+}$ load in dominant and $\mathrm{Na}^{+}$load in subsidiary pacemakers.

To maintain homeostasis, ions moving across the cell membrane during systole must be returned to their original environment during diastole. $\mathrm{Ca}^{2+}$ is extruded in exchange for extracellular $\mathrm{Na}^{+}$by the $\mathrm{Na}^{+}-\mathrm{Ca}^{2+}$ exchange current in the forward mode [14], whereas $\mathrm{Na}^{+}$is extruded in exchange with extracellular $\mathrm{K}^{+}$by the $\mathrm{Na}^{+}-\mathrm{K}^{+}$ pump [15]. Both the extrusion of $\mathrm{Na}^{+}$and of $\mathrm{Ca}^{2+}$ are electrogenic, although the pump current is outward [15] and the exchange current NCX at diastolic potentials is inward [14].

The loading of different ions during a faster discharge would be expected to have important physiological implications for SAN pacemaker activity. In dominant pacemaker cells, a prevalent extrusion of $\mathrm{Ca}^{2+}$ would steepen the slope of diastolic depolarization whereas in subsidiary pacemakers a prevalent extrusion of $\mathrm{Na}^{+}$would decreases it. In fact, overdrive of the cat SAN subsidiary pacemaker region surgically separated from the dominant region is followed by a prolonged inhibition [8], as in Purkinje fibers ("overdrive suppression", [10]). Conversely, when in high $\left[\mathrm{K}^{+}\right]_{\mathrm{o}}$ SAN action potentials acquire the characteristics of dominant responses [16-20], overdrive may enhance or induce spontaneous discharge [18, 20] ("overdrive excitation", [21]).

The general aim of the present experiments was to investigate the hypothesis that in the SAN overdrive can cause excitation under conditions that increase $\mathrm{Ca}^{2+}$ load and suppression under conditions that increase the $\mathrm{Na}^{+}$load; and that the short pause induced by overdrive in SAN discharge may be the net result of an electrotonic interplay between these opposite mechanisms. Since the electrical changes associated with overdrive have been reported $[8,18,20]$, the main focus was on force behavior, as it gives essential insights on both $\mathrm{Ca}^{2+}$ changes on a beat to beat basis and simultaneous rate changes.

The specific aims were to: (i) verify the effects of overdrives of different duration and rate on force and discharge patterns in Tyrode solution (both dominant and subsidiary pacemakers are present); (ii) study the effects of a prevalent $\mathrm{Ca}^{2+}$ loading by depolarizing the pacemaker cells in high $\left[\mathrm{K}^{+}\right]_{\mathrm{o}}$ (slow responses prevail); (iii) use different patterns of drive to determine if $\mathrm{Ca}^{2+}$ extrusion is impaired when the cells have a less negative diastolic potential; and (iv) use blockers of either $\mathrm{Ca}^{2+}$ or $\mathrm{Na}^{+}$channels to decrease the load of these ions; and (v) increase the entry of $\mathrm{Ca}^{2+}$ by using higher $\left[\mathrm{Ca}^{2+}\right]_{0}$ or $\mathrm{Ba}^{2+}$.

\section{Materials and methods}

The procedures concerning the animals used were in accordance with national and institutional guidelines. Hartley guinea pigs $(259.0 \pm 12.2 \mathrm{~g})$ of either sex were euthanized with an overdose of sodium pentobarbital $(60 \mathrm{mg} / \mathrm{kg}$ intraperitoneally). The heart was rapidly excised and placed in a Petri dish filled with oxygenated Tyrode solution. The SAN was identified as a translucent whitish area and was separated from surrounding redbrown atrial tissue. The SAN of guinea pig is thin (and therefore well superfused in vitro) and is made up of SAN cells throughout its thickness [22].

The SAN was superfused at $37^{\circ} \mathrm{C}$ with gassed $\left(95 \% \mathrm{O}_{2}\right.$ and $\left.5 \% \mathrm{CO}_{2}\right)$ Tyrode solution of the following composition (mM): $\mathrm{NaCl} \mathrm{129,} \mathrm{KCL} 4$, $\mathrm{CaCl}_{2}$ 2.7, $\mathrm{NaHCO}_{3} 20, \mathrm{NaH}_{2} \mathrm{PO}_{4} 0.45, \mathrm{MgCl}_{2}$ 1.05 and glucose 5.5. To analyze the effect of a fast rate on predominantly dominant pacemaker activity, $\left[\mathrm{K}^{+}\right]_{\mathrm{o}}$ was increased by mixing the Tyrode solution with a solution containing $40 \mathrm{mM} \mathrm{KCl}$ (but otherwise identical with Tyrode solution and gassed with the same mixture). The flow of Tyrode solution was kept constant at $1.71 \mathrm{ml} / \mathrm{min}$ and the flow of the $\mathrm{K}^{+}$-rich solution was changed by means of a peristaltic pump (LKB Broma, model 12000 Perpex) over the range $0-1.54 \mathrm{ml} / \mathrm{min}$ in different tests. The two solutions mixed before entering the thermostatic bath and tissue chamber. $\left[\mathrm{K}^{+}\right]_{\mathrm{o}}$ of the final admixture was calculated by means of the following equation:

$$
K=\frac{\mathrm{F}_{\mathrm{T}} \cdot \mathrm{K}_{\mathrm{T}}+\mathrm{F}_{\mathrm{K}} \cdot \mathrm{K}_{\mathrm{K}}}{\mathrm{F}_{\mathrm{T}}+\mathrm{F}_{\mathrm{K}}}
$$


where $K$ is $\left[\mathrm{K}^{+}\right]_{\mathrm{o}}$ in the bath, $\mathrm{F}_{\mathrm{T}}$ is the Tyrode flow, $\mathrm{K}_{\mathrm{T}}$ is $\left[\mathrm{K}^{+}\right]_{\mathrm{o}}$ in Tyrode, $\mathrm{F}_{\mathrm{K}}$ is the flow of the $\mathrm{K}^{+}$-rich solution and $\mathrm{K}_{\mathrm{K}}$ is $\left[\mathrm{K}^{+}\right]_{\mathrm{o}}$ in the $\mathrm{K}^{+}$-rich solution. The effects of a higher $\mathrm{K}^{+}$were quickly established ( $<5 \mathrm{~min})$ : once a new steady-state was attained, tests were carried out as warranted. The increase in $\left[\mathrm{K}^{+}\right]_{\mathrm{o}}$ was adjusted for each SAN to a value that resulted in slowing or in quiescence, as required by different procedures. $\left[\mathrm{Ca}^{2+}\right]_{0}$ was increased by directly adding $\mathrm{CaCl}_{2}$ to oxygenated freshly prepared Tyrode solution.

Spontaneously discharging SAN was held at one end by means of a double-tipped stainless steel electrode and at the other end by a short silk thread attached to the rigid rod of a force transducer (Grass Model FTO3C). The force transducer was coupled to a Grass Model 7D Polygraph. Membrane potentials were recorded by means of microelectrodes filled with $3 \mathrm{M} \mathrm{KCl}$ and coupled to a Dagan probe and to a Dagan model 8500 operational amplifier. The traces were displayed on a Tektronix model 5111 storage oscilloscope and recorded on paper on a three channel chart recorder (Gould Brush 2400S). The preparations were allowed to equilibrate for about $1 \mathrm{~h}$ in the tissue bath before beginning the experiment. The electrical stimuli were provided by a Grass 8800 Stimulator and were applied between the electrode holding the SAN and an electrode placed in the solution near the force transducer.

Tetrodotoxin, lidocaine, $\mathrm{CsCl}, \mathrm{BaCl}_{2}$ (Sigma Chemical Co.) and $\mathrm{NiCl}_{2}$ (Fluka Chemika) were used. The results of the tests performed $(n)$ are expressed as means \pm standard error of the mean (SEM). Student's paired $t$ test between two terms of comparison, ANOVA between data groups and the Page Test of ordered alternatives [23] to determine whether the mean values statistically changed in a monotonic manner were applied: a $p<0.05$ was considered significant (marked in the text by an asterisk *, paragraph sign $\S$ and two crosses $\ddagger$, respectively).

\section{Results}

Effects of overdrives of different duration and rate in Tyrode solution

In Tyrode solution, both dominant and subsidiary pacemaker action potentials are present $[8,11-13]$.
Therefore, increasing the duration or rate of overdrive might have little effect on the pause if opposing mechanisms are both enhanced and electrotonically interact.

In Figure 1A, a 300/min overdrive was applied for $5,10,30$ and $60 \mathrm{~s}$. During overdrive, force initially decreased and then re-increased toward a new steady state value which was greater than the pre-drive value. The resting force also increased, but this was due to diastole being too short during overdrive to allow full relaxation of the twitch, as seen by the fact that the last driven beat relaxed to control resting tension during the longer diastole. After the $5 \mathrm{~s}$ drive, the pause was longer than control cycle length $(+16.2 \%)$ and was followed by a more forceful twitch. After the pause, the rate and the markedly increased contraction subsided back to the control value. When the duration of drive was increased to 10,30 and $60 \mathrm{~s}$, the duration of the pause increased very little, whereas force increased more.

In Figure 1B, the average results $(n=19)$ show that during $5 \mathrm{~s}$ overdrive force decreased at the beginning of drive $\left(\mathrm{DF}_{1}\right)$ below control and it increased by the end of drive $\left(\mathrm{DF}_{2}\right)$ above control, and more so the longer the drives. After the $5 \mathrm{~s}$ drive, the pause was longer than control cycle length $(+23.2 \%)$ and changed little after longer drives. The first beat after the pause $\left(\mathrm{PDF}_{1}\right)$ became larger with longer drives and was followed by a slight slowing of the early rate $\left(\mathrm{PDR}_{1}\right)$. During late recovery, the rate $\left(\mathrm{PDR}_{2}\right)$ and force $\left(\mathrm{PDF}_{2}\right)$ were similar to control, suggesting a complete extrusion of extra $\mathrm{Ca}^{2+}$ entered during overdrive.

The results with faster drives are reported in Table $1 . \mathrm{PDF}_{1}$ and $\mathrm{PDF}_{2}$ increased more after the faster (375/min) drive and yet, the pause and rate immediately after pause were much less affected. Thus, in Tyrode solution, the pause was less affected than force by longer or faster overdrives.

\section{Drive-dependent suppression and excitation in high $\left[\mathrm{K}^{+}\right]_{o}$}

$\left[\mathrm{K}^{+}\right]_{\mathrm{o}}$ was increased in order to decrease the diastolic potential, so that all SAN cells tend to assume the configuration of the slow response action potential [17-20].

In Figure 2A, the same SAN as in Figure 1 was superfused in high $\left[\mathrm{K}^{+}\right]_{\mathrm{o}}$ and the same drives were 

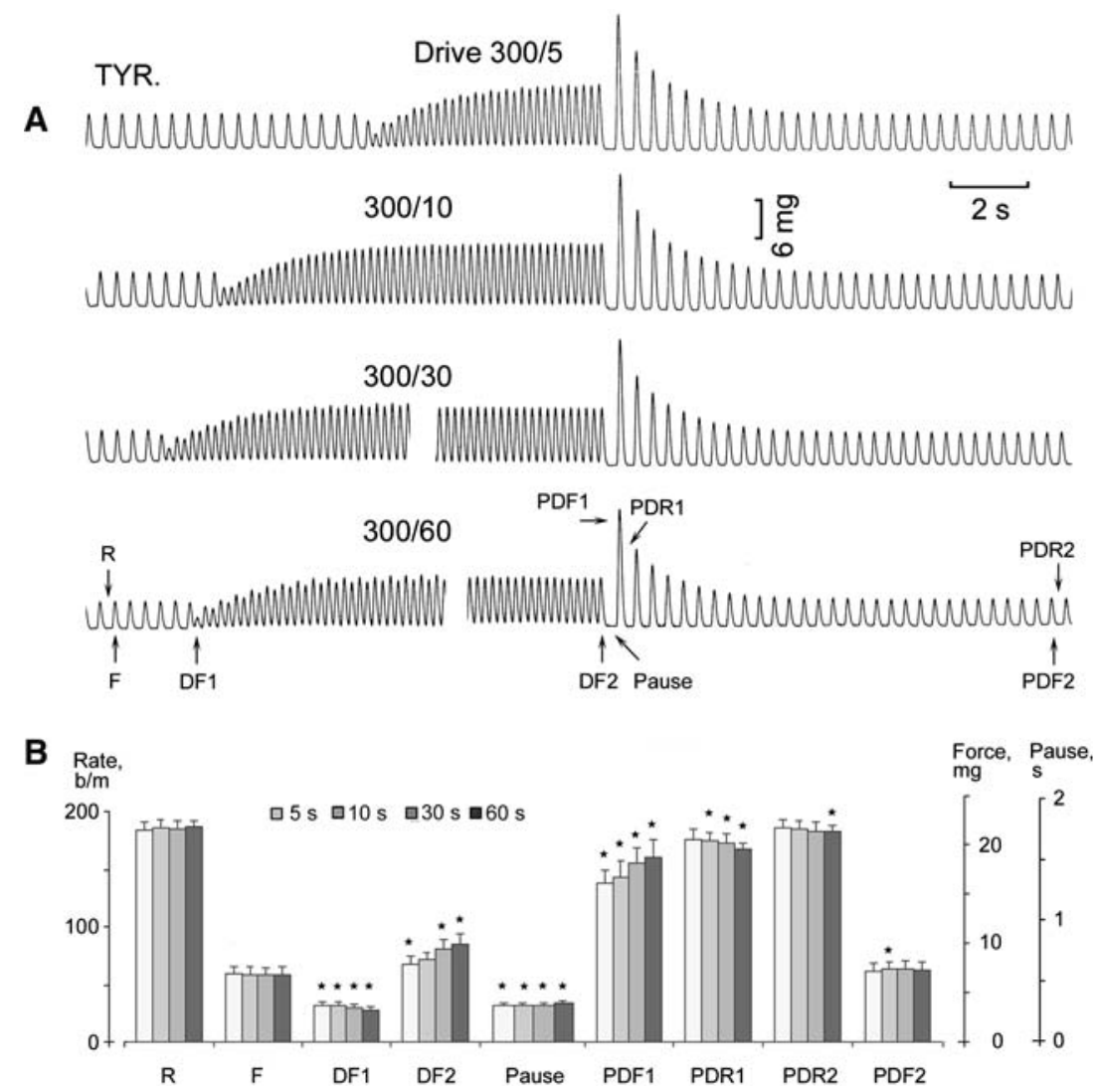

Figure 1. Effects of overdrives of different duration in Tyrode solution. The traces are a record of contractile force. In A, rate and duration of overdrives are indicated above the traces. In $\mathrm{B}$, the graph shows the average results. $\mathrm{R}=$ control rate in beats $/$ min; $\mathrm{F}=$ control force in $\mathrm{mg} ; \mathrm{DF}_{1}=$ force of the first driven beat in $\mathrm{mg} ; \mathrm{DF}_{2}=$ force of the last driven beat in mg; pause = time interval between the last driven beat and the first spontaneous beat in $\mathrm{s}$; $\mathrm{PDF}_{1}=$ first contraction in $\mathrm{mg}$ after the pause; $\mathrm{PDR}_{1}=$ rate in beats $/ \mathrm{min}$ immediately after the pause; $\mathrm{PDR}_{2}=$ late post-drive rate in beats $/ \mathrm{min} ; \mathrm{PDF}_{2}=$ late post-drive force in $\mathrm{mg}$. In this and in the following figures, the number before the division sign indicates the rate of drive (e.g., 300 stimuli per minute) and number after the division sign indicate the duration of the drive (e.g., $5 \mathrm{~s})$. The asterisk $(*)$ indicate a statistical difference with the respective control. The pause duration was compared with the control cycle length.

carried out. In high $\left[\mathrm{K}^{+}\right]_{\mathrm{o}}$ (which decreases $I_{\mathrm{Ca}}$ [24]), the rate was slower and force smaller than in Tyrode solution. This may be reflected also in the fact that during the shorter drives (5 and $10 \mathrm{~s}$ ) force did not increased above pre-drive value. The $5 \mathrm{~s}$ drive was followed by a marked suppression. After the pause, the twitch was large, but force decreased markedly and quickly to control value. The $10 \mathrm{~s}$ drive showed similar characteristics, but the pause was somewhat shorter and $\mathrm{PDF}_{1}$ greater.

By the end of the 30 and $60 \mathrm{~s}$ drives, force had increased above the pre-drive value and the pauses were much shorter than after the 5 and 10 s drives.

Table 1. Effects of faster drive on rate and force patterns.

\begin{tabular}{llllllll}
\hline$n=5$ & $\mathrm{DF}_{1}$ & $\mathrm{DF}_{2}$ & Pause & $\mathrm{PDF}_{1}$ & $\mathrm{PDR}_{1}$ & $\mathrm{PDR}_{2}$, & $\mathrm{PDF}_{2}$ \\
\hline $300 / \mathrm{min}$ & -39.5 & +56.2 & +25 & +177 & -6.2 & +2.8 & +4.2 \\
$375 / \mathrm{min}$ & $-55.7^{*} \#$ & +54.7 & $+32.9^{*} \#$ & $+369.0^{*} \#$ & -8 & +4.3 & $+7.1^{*} \#$ \\
\hline
\end{tabular}

$n=$ number of tests. $\mathrm{DF}_{1}, \mathrm{DF}_{2}$, pause, $\mathrm{PDF}_{1}, \mathrm{PDR}_{1}, \mathrm{PDR}_{2}, \mathrm{PDF}_{2}=$ as explained in legend of Figure 1. 300/min and 375/ $\min =$ rates of $10 \mathrm{~s}$ overdrives. * Statistically different from their own control values; \# Statistically different from values in the top row. 
The first contraction after the $60 \mathrm{~s}$ drive was larger than that after the $30 \mathrm{~s}$ drive (at the end of two drives, force was 6.3 and $4.8 \mathrm{mg}$, respectively). As emphasized in the boxed insets $a$ and $b$, after the drives force and rate increased above control (overdrive excitation). When $\left[\mathrm{K}^{+}\right]_{\mathrm{o}}$ was increased to $11.0 \mathrm{mM}$, the SAN became quiescent (not shown): overdrive (after a brief pause) actually induced fast discharge $(146.3 / \mathrm{min})$ which continued for several tens of seconds.

In Figure $2 \mathrm{~B}\left(n=13,\left[\mathrm{~K}^{+}\right]_{\mathrm{o}}=13.6 \pm 1.2 \mathrm{mM}\right)$, longer drives $(270.0 \pm 8.3 / \mathrm{min}$ for $5,10,30$ and $60 \mathrm{~s})$ gradually more increased force $\left(\mathrm{DF}_{2}, \S \ddagger\right.$ $\mathrm{PDF}_{1}, \S \ddagger$ ) above control (and more so than in Tyrode solution), markedly diminished the pause $(\ddagger)$, caused a subsequent acceleration $\left(\mathrm{PDR}_{1}\right.$ and $\left.\mathrm{PDR}_{2}, \S \ddagger\right)$ and markedly slowed the force decline after the drives $\left(\mathrm{PDF}_{2} \S \ddagger\right)$. Thus, in high $\left[\mathrm{K}^{+}\right]_{\mathrm{o}}$ faster drives induce overdrive excitation as they increase force and rate, and shorten the pause.

\section{Changes in force at constant rate after overdrives}

In high $\left[\mathrm{K}^{+}\right]_{\mathrm{o}}$, the greater increase in force during and the slower decline of force and rate after longer drives suggest the possibility that a decreased $\mathrm{Ca}^{2+}$ extrusion might contribute to the enhanced force and rate. If so, in non-spontaneous SAN driven at $6 / \mathrm{min}$ and overdriven for $2 \mathrm{~min}$ at progressively faster rates, a decreased $\mathrm{Ca}^{2+}$ extrusion should be reflected in the magnitude and decay of force during recovery from overdrive, the rate being constant at 6/min.

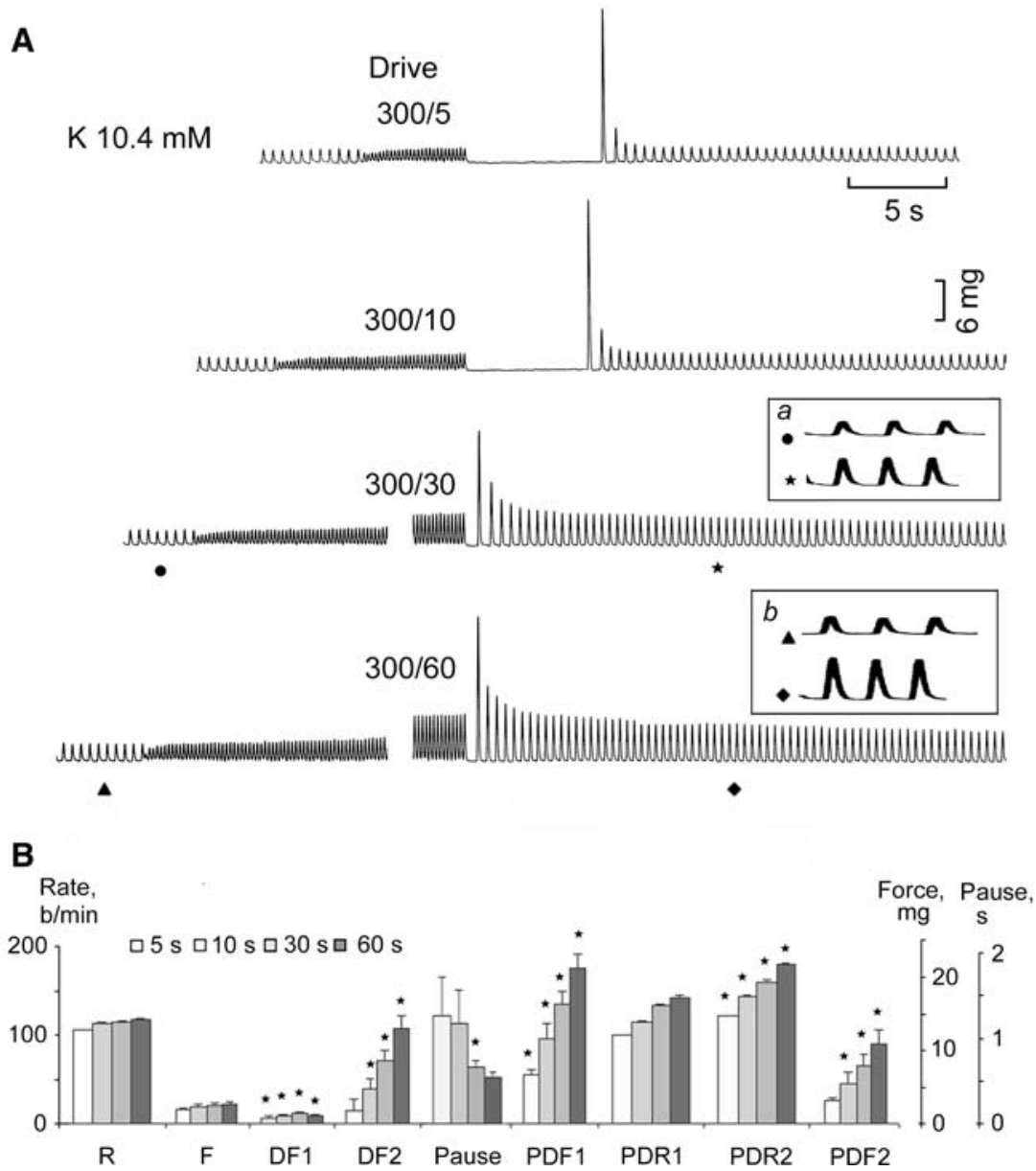

Figure 2. Effects of overdrives of different duration in high $\left[\mathrm{K}^{+}\right]_{\mathrm{o}}$. In A, the SAN was spontaneously active in $10.4 \mathrm{mM}\left[\mathrm{K}^{+}\right]_{\mathrm{o}}$ and was overdriven at the rate and for the durations indicated. The same symbols identify the same traces within and without the boxed inset $a$ and $b$. In $\mathrm{B}$, the average values are shown. Other explanation as in legend of Figure 1. 
A
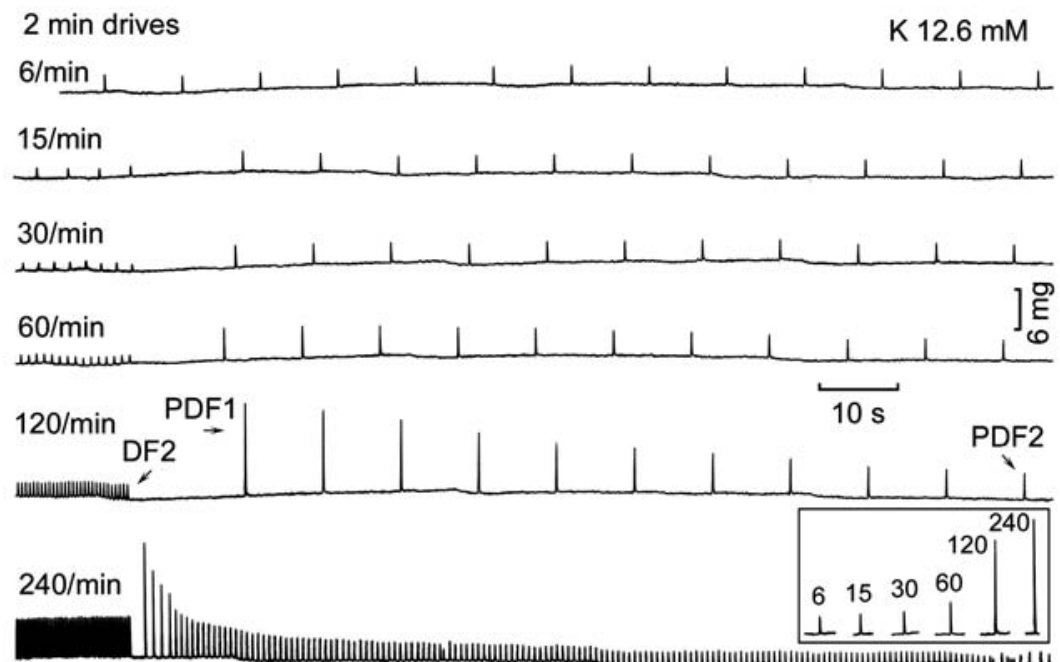

B

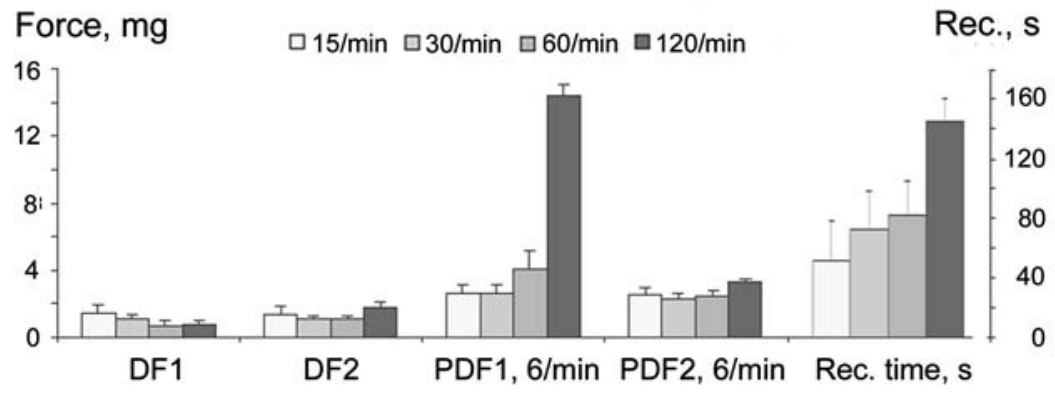

Figure 3. Effect of drives of increasing frequency and fixed duration on the subsequent behavior of force in high $\left[\mathrm{K}^{+}\right]_{\mathrm{o}}$. In $\mathrm{A}$, the rates of the 2 min overdrives are indicated above the respective traces. After the overdrives, 6/min drive was resumed, except for the bottom trace where overdrive induced excitation. In the boxed inset, the first beat after the ovedrive indicated by numbers is shown. In $\mathrm{B}$, the average values are shown for force of the first beat of overdrive $\left(\mathrm{DF}_{1}\right)$, of the last beat of overdrive $\left(\mathrm{DF}_{2}\right)$, of the first post-drive beat $\left(\mathrm{PDF}_{1}\right)$, and of a late post-drive beat $\left(\mathrm{PDF}_{2}\right)$ in $\mathrm{mg}$, as well as recovery intervals in seconds

In Figure 3A, during the 6/min drive force was constant (top trace). At the beginning of 30, 60, 120 and $240 / \mathrm{min}$ drives force decreased with respect to that during the preceding $6 / \mathrm{min}$ drive (not shown). At the end of 15, 30, 60, 120 and 240/min drives, force had increased by $0,+6.2,+66.6,+281.8$ and $+900 \%$, respectively, with respect to the first beat of the overdrives. After the 15, 30, 60 and $120 / \mathrm{min}$ drives, the first beat at $6 / \mathrm{min}$ drive was $+117.3,+235.2,+305.0$ and $+447.0 \%$, respectively, above the last beat of the previous drive (see boxed inset). After an initial brief pause, the $240 /$ min drive induced overdrive excitation. After the overdrives, recovery of force took longer the faster the previous drive.

In Figure 3B $(n=4)$, force became gradually smaller at the beginning of $15,30,60,120 / \mathrm{min}$ drives $\left(\mathrm{DF}_{1}, \ddagger\right)$ and gradually larger by the end of the same drives $\left(\mathrm{DF}_{2}, \S \ddagger\right)$ compared to $\mathrm{DF}_{1}$. After overdrives, at 6/min $\mathrm{PDF}_{1}$ was larger than $\mathrm{DF}_{2}$ and more so with longer drives $(\S, \ddagger p=0.079)$ and then decreased to a similar value $\left(\mathrm{PDF}_{2} \sim 2.5 \mathrm{mg}\right)$ after gradually longer periods (Recovery time). In $n=2,240$ and $300 / \mathrm{min}$ drives were followed by overdrive excitation with a strong initial contraction. Thus, during a steady slow post-overdrive rhythm, the greater force takes a gradually longer time to decrease to the original value.

\section{Effects of intermittent drives on force in quiescent $S A N$}

If force increases with overdrives also because of a slower $\mathrm{Ca}^{2+}$ extrusion (as suggested by the above 
results), then in quiescent SAN successive drives at the same rate separated by periods of quiescence of the same duration as the drives may lead to a progressive increase in force. This approach also allows to test how long the quiescence needs to last for force to return to control patterns.

In Figure $4 \mathrm{~A}$, in SAN quiescent in high $\left[\mathrm{K}^{+}\right]_{\mathrm{o}}$, $10 \mathrm{~s}$ drives were separated by $10 \mathrm{~s}$ periods of quiescence. During successive drives, force gradually increased, but from a gradually greater initial value. Thus, in the top $B$ trace (last drive of the series), the first $\left(F_{1}\right)$ and second $\left(F_{2}\right)$ beat after quiescence, and the last beat $\left(\mathrm{F}_{3}\right)$ of drive increased by $+88.8,+1528.5$ and $+222.2 \%$, respectively, in comparison to $F_{1}, F_{2}$ and $F_{3}$ of the first drive (top A trace). Eventually, force stabilized during the drives as a new steady state was attained.

To verify how long quiescence needs to be in order to restore control force patterns (top A trace), in Figure 4B the quiescent period preceding the $10 \mathrm{~s}$ drive was gradually increased. When drives where separated by three successive pauses of $30 \mathrm{~s}$ each, the increase in force began to subside, but only after additional pauses of 60 and $120 \mathrm{~s}$ did force return to the initial patterns.

An average of $11.8 \pm 1.8$ drives of $10 \mathrm{~s}$ duration and $274.2 \pm 12.1 / \mathrm{min}$ rate were separated by $10 \mathrm{~s}$ periods of quiescence. In Table 2, force during the last drive was greater than during the first drive, with the greatest increment in $\mathrm{F}_{2}$. In two additional experiments, the intermittent drives induced spontaneous discharge.

\section{Intermittent drives of active $S A N$ in Tyrode solution and in high $\left[\mathrm{K}^{+}\right]_{o}$}

In quiescent SAN, the lack of activity allowed to study the effects on force of repeated drives separated by equal periods of quiescence. However, since overdrive appears to affect not only force but also the rate, the effects of intermittent drives on force and rate were also studied in spontaneously active SAN.

In Figure 5A, in Tyrode solution, the first, second, fourth and seventh drives were followed by similarly short pauses and by an increase in force that subsided in less than $5 \mathrm{~s}$ after the pause. That less than $5 \mathrm{~s}$ were needed for the subsiding of the increase in force was verified by reducing the non-driven interval to $5 \mathrm{~s}$ for five times. The 12th drive was followed by the fifth shorter interval and still force fell to a steady state by the end of $5 \mathrm{~s}$. The behavior of force was similar after the last (15th) drive.

In Figure 5B, in high $\left[\mathrm{K}^{+}\right]_{\mathrm{o}}$, the first drive (top B trace) was followed by a relatively long pause, a larger beat and a subsequent acceleration
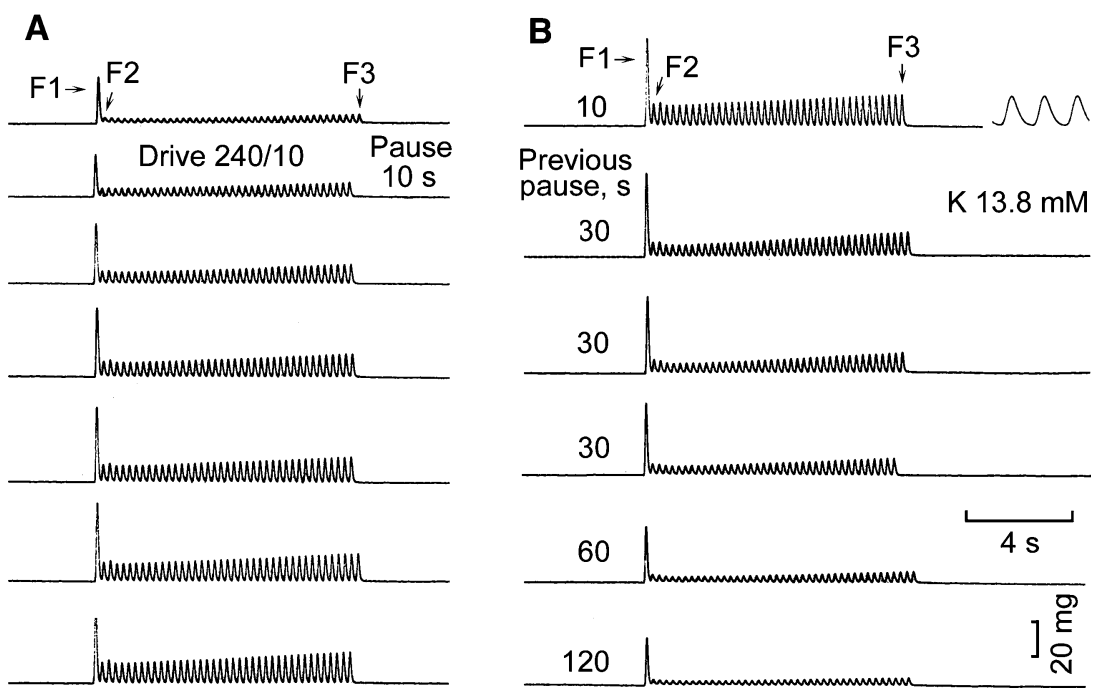

Figure 4. Effects of intermittent drives on force development in high $\left[\mathrm{K}^{+}\right]_{\mathrm{o}}$. In A, repeated $240 / \mathrm{min} 10 \mathrm{~s}$ drives separated by $10 \mathrm{~s}$ pauses were applied to a SAN quiescent in $13.8 \mathrm{mM}\left[\mathrm{K}^{+}\right]_{\mathrm{o}}$. In $\mathrm{B}$, the duration of the pauses is indicated by the numbers (in seconds) next to the traces. $F_{1}$ indicates the force of the first beat after the pause, $F_{2}$ the force of the second beat and $F_{3}$ the force of the last beat of the drives. 
Table 2. Effects of intermittent drives on force in quiescent SAN.

\begin{tabular}{llll}
\hline $\begin{array}{l}n=7,\left[\mathrm{~K}^{+}\right]_{\mathrm{o}} \\
14.5 \pm 1.1 \mathrm{mM}\end{array}$ & $\mathrm{F}_{1}$ & $\mathrm{~F}_{2}$ & $\mathrm{~F}_{3}$ \\
\hline First drive & $9.9 \pm 3.2$ & $0.15 \pm 0.06$ & $1.5 \pm 0.66$ \\
Last drive & $24.1 \pm 4.7^{*}$ & $3.9 \pm 1.5^{*}$ & $7.5 \pm 2.4^{*}$ \\
$\%$ Change & $+141.5 \%$ & $+2464.0 \%$ & $+379.2 \%$ \\
\hline
\end{tabular}

First drive $=$ results obtained with the first drive. Last dri$\mathrm{ve}=$ results obtained with the last drive. $\mathrm{F}_{1}, \mathrm{~F}_{2}, \mathrm{~F}_{3}=$ force in $\mathrm{mg}$ of the first, the second and the last beat of drive, respectively. \% Change $=$ percent increase in $\mathrm{F}_{1}, \mathrm{~F}_{2}$ and $\mathrm{F}_{3}$ during the last drive compared to the first. * Statistically different from values in top row.

$(+108.5 \%$ of the pre-drive rate). After the successive drives, the pause gradually decreased, and the faster spontaneous discharge started earlier and was associated with a greater force. At the end of the last (11th) drive, force was $+240 \%$, the pause $-56.5 \%$ and the spontaneous rate $+59.1 \%$ with respect to the first drive. During the recovery from the 11 th drive, force and rate decreased but slowly.

In Figure 5C, in Tyrode solution, the changes in rate and force for the last drive with respect to the first are small and quickly decaying. In Figure $5 \mathrm{D}$, in high $\left[\mathrm{K}^{+}\right]_{\mathrm{o}}$, the changes with the last drive with respect to the first show that repeated drives increase both force and rate, and decrease the pause.

\section{Effects of cesium on overdrive patterns in Tyrode solution}

High $\mathrm{Cs}^{+}$depolarizes the SAN and reduces its spontaneous discharge [16], as high $\left[\mathrm{K}^{+}\right]_{\mathrm{o}}$ does.

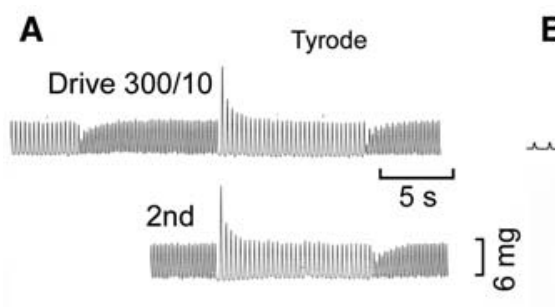

B
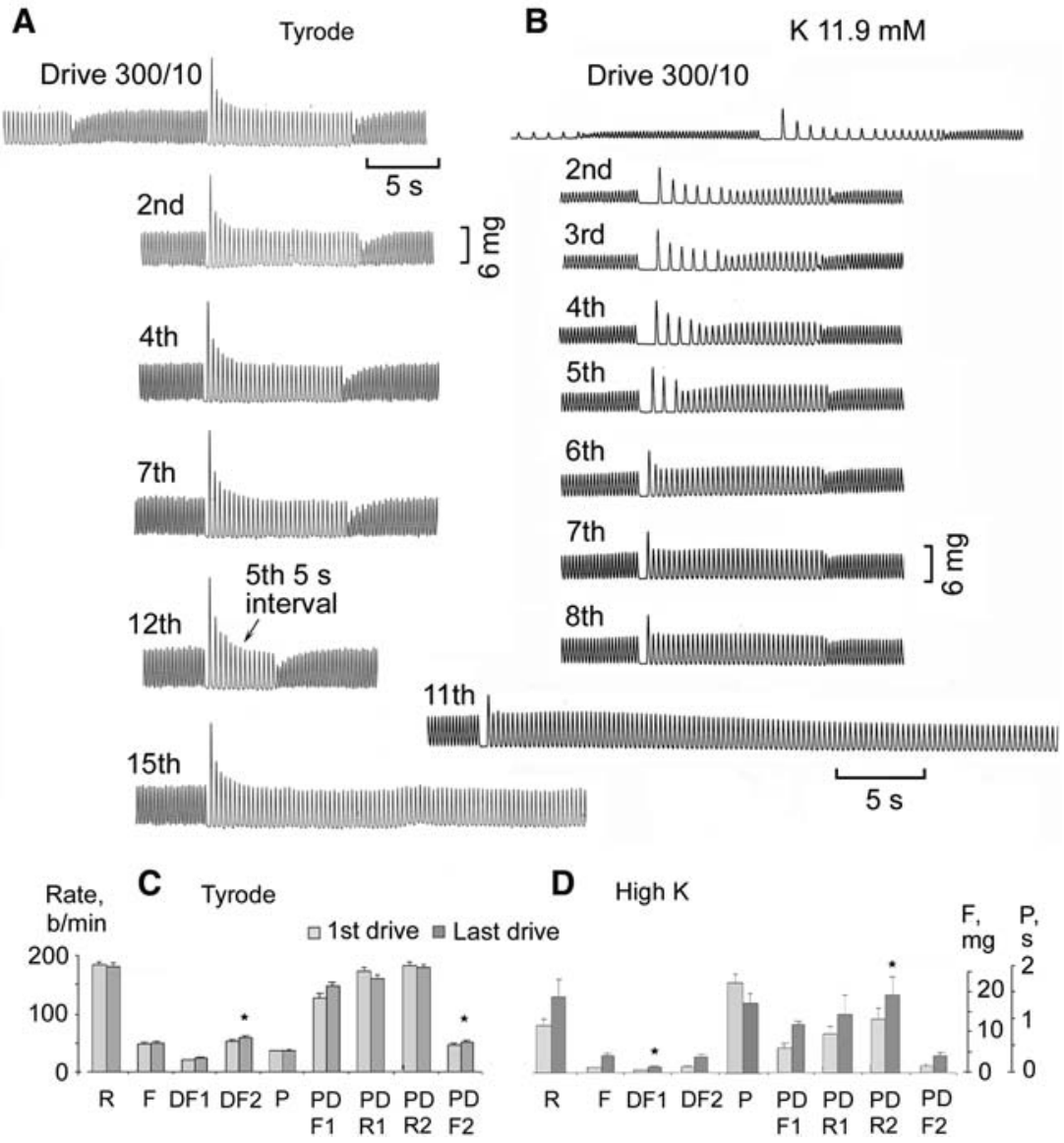

Figure 5. Effects of intermittent drives on force and rate in active SAN in Tyrode solution and in high $\left[\mathrm{K}^{+}\right]_{\mathrm{o}}$. In $\mathrm{A}$, repeated $300 /$ min $10 \mathrm{~s}$ drives separated by $10 \mathrm{~s}$ pauses were applied to a SAN perfused in Tyrode solution and in B to an active SAN in $11.9 \mathrm{mM}\left[\mathrm{K}^{+}\right]_{\mathrm{o}}$. Successive traces are identified by the numbers next to them. In A, the five pauses preceding the 12th drive were reduced to $5 \mathrm{~s}$. The average values for the first and last drive in Tyrode solution are shown in $\mathrm{C}$ and those in high $\left[\mathrm{K}^{+}\right]_{\mathrm{o}}$ in $\mathrm{B}$. 
If high $\left[\mathrm{K}^{+}\right]_{0}$ impairs $\mathrm{Ca}^{2+}$ extrusion by decreasing the diastolic potential, then high $\mathrm{Cs}^{+}$may lead to effects similar to those by high $\left[\mathrm{K}^{+}\right]_{\mathrm{o}}$.

In Figure 6A, in Tyrode solution, overdrive induced a pause followed by a slight acceleration of discharge (see boxed inset $a$, where the same symbols identify the same traces within and without the inset). In Figure $6 \mathrm{~B}$, in $15 \mathrm{mM} \mathrm{Cs}^{+}$, the subsidiary action potentials recorded in Tyrode solution (TYR.) underwent a considerable depolarization (emphasized by the dashed line) and the development of a diastolic tail (see grey area) $[16,25,26]$ while rate and force decreased. In $\mathrm{Cs}^{+}$, overdrive increased force more slowly, was followed by a longer pause $(+203.5 \%$ of the predrive cycle length), a larger first beat and a substantial acceleration of discharge (see boxed inset $b$ ). The increase in rate and force subsided slowly during recovery from overdrive, as also seen with high $\left[\mathrm{K}^{+}\right]_{\mathrm{o}}$.

In Figure 6C $(n=5)$, with respect to Tyrode control, in $15 \mathrm{mM} \mathrm{Cs}^{+}$all parameters (except the pause) decreased. Nevertheless, in the presence of $\mathrm{Cs}^{+}$, overdrive increased percentage-wise rate and force more than in Tyrode, as it does in high $\left[\mathrm{K}^{+}\right]_{\mathrm{o}}$.
Effects of high $\left[\mathrm{Ca}^{2+}\right]_{0}$ on overdrive patterns

If the changes induced by drives are related to a progressive increase in $\left[\mathrm{Ca}^{2+}\right]_{i}$, then increasing $\mathrm{Ca}^{2+}$ load by increasing $\left[\mathrm{Ca}^{2+}\right]_{\mathrm{o}}$ should enhance the excitatory effects of drive on force and rate, but not necessarily to the same extent in Tyrode and high $\left[\mathrm{K}^{+}\right]_{\mathrm{o}}$ solutions.

In Figure 7A, in Tyrode solution, high $\left[\mathrm{Ca}^{2+}\right]_{\mathrm{o}}$ increased the rate slightly and force markedly (note the different force calibrations). During overdrive, force reached a steady state sooner (cf. dashed lines and gray areas). During drive, the first beat decreased less than in control and there was a small decrease in the steady state force. After drive, the pause was similar to control and the absolute value of the first beat after the pause was greater in high $\left[\mathrm{Ca}^{2+}\right]_{\mathrm{o}}(79.2 \mathrm{mg})$ than in control $(49.8 \mathrm{mg})$. Early post-drive rate was slightly slower than pre-drive rate.

In Figure $7 \mathrm{~B}$, in high $\left[\mathrm{K}^{+}\right]_{\mathrm{o}}$, the smaller force increased more slowly but substantially during drive, as usual. Rate and force were greater after drive than before (upper traces in boxed inset). In the bottom $\mathrm{B}$ trace, high $\left[\mathrm{Ca}^{2+}\right]_{0}$ increased rate and force (note the different force calibrations), as also shown by a comparison of the left traces in

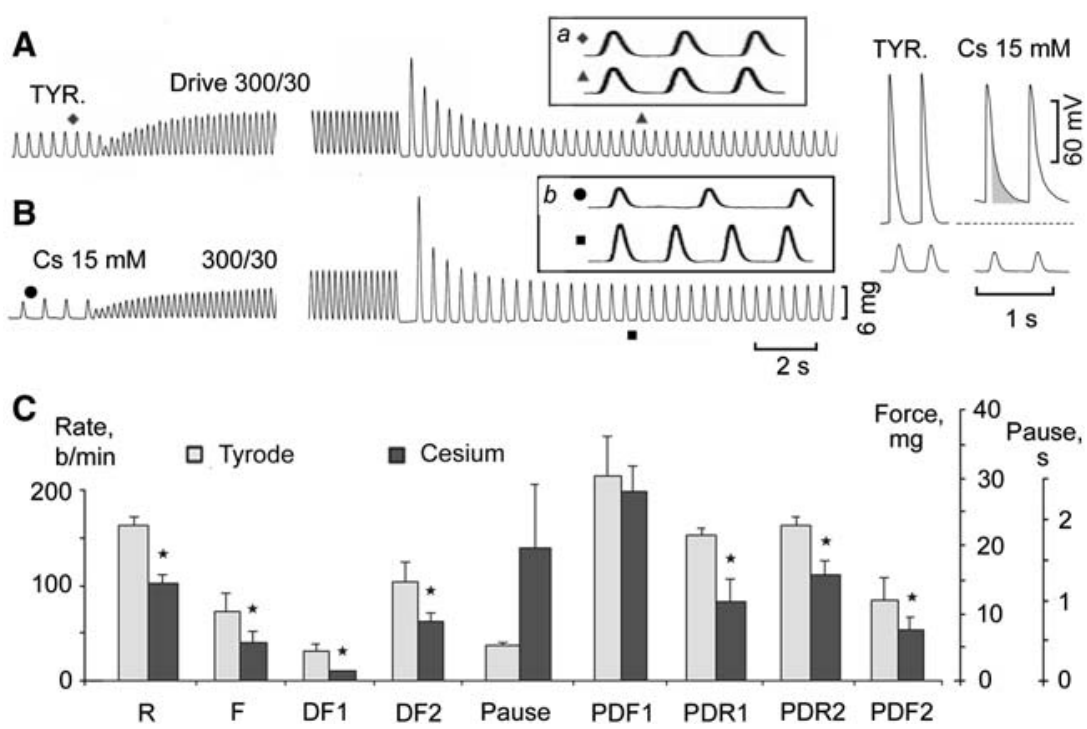

Figure 6. Effects of high cesium on rate and force overdrive patterns. In A and B, the same symbols identify the same traces within and without the boxed insets $a$ and $b$. The action potentials and twitches were recorded in Tyrode solution and in $15 \mathrm{mM}$ cesium, as indicated. The dashed line extrapolates the maximum diastolic potential in Tyrode solution and the grey area the $\mathrm{Cs}^{+}$-induced tail. In C, the average values in Tyrode solution and in the presence of $\mathrm{Cs}^{+}$are shown. 

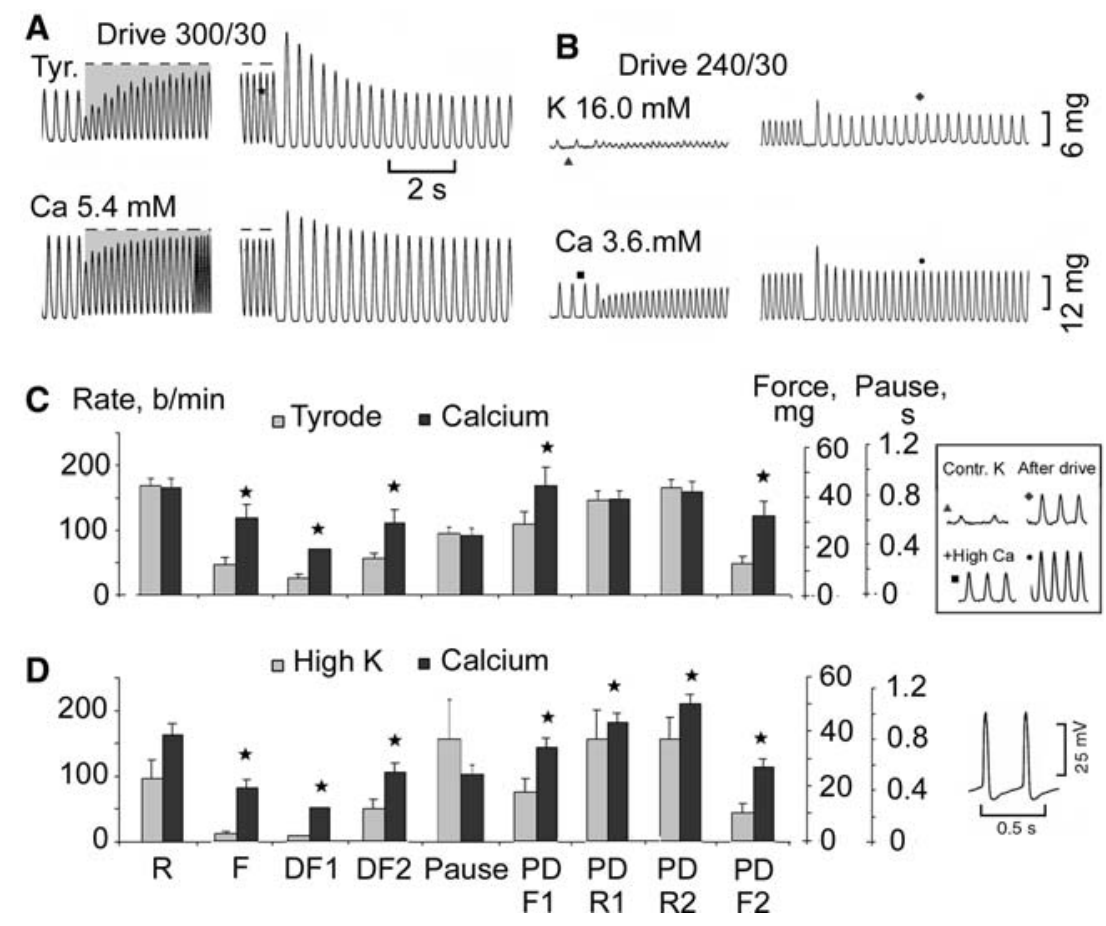

Figure 7. Effects of high $\left[\mathrm{Ca}^{2+}\right]_{\mathrm{o}}$ on rate and force overdrive patterns. In A, the top trace was recorded in Tyrode solution and bottom trace in the presence of $5.4 \mathrm{mM}\left[\mathrm{Ca}^{2+}\right]_{\mathrm{o}}$. The grey areas and dashed lines emphasize the more rapid increase in force during drive in high $\left[\mathrm{Ca}^{2+}\right]_{\mathrm{o}}$. In $\mathrm{B}$, drive was repeated in $16.0 \mathrm{mM}\left[\mathrm{K}^{+}\right]_{\mathrm{o}}$ (top trace) and in high $\left[\mathrm{K}^{+}\right]_{\mathrm{o}}$ plus $3.6 \mathrm{mM}\left[\mathrm{Ca}^{2+}\right]_{\mathrm{o}}($ bottom trace). The same symbols identify the same trace within and without the boxed inset. The action potentials were recorded in high $\left[\mathrm{K}^{+}\right]_{\mathrm{o}}$. The average values of $\mathrm{Ca}^{2+}$ effects are shown in $\mathrm{C}$ for Tyrode solution and in $\mathrm{D}$ for high $\left[\mathrm{K}^{+}\right]_{\mathrm{o}}$.

the boxed inset. By the end of drive, force had increased above the pre-drive value. After drive, while the pause was little altered in high $\left[\mathrm{Ca}^{2+}\right]_{\mathrm{o}}$, both the late post-drive rate and force were greater than prior to overdrive (cf. bottom traces in boxed inset), and decreased very slowly.

In Figure 7C $(n=7)$ in Tyrode solution, $5.4 \mathrm{mM}\left[\mathrm{Ca}^{2+}\right]_{0}$ changed little the rate, but more than doubled force. In high $\left[\mathrm{Ca}^{2+}\right]_{\mathrm{o}}, 30 \mathrm{~s} 300 / \mathrm{min}$ overdrive substantially increased force parameters, but had little effect on the rate. Shorter drives (5 and $10 \mathrm{~s}$ ) showed trends similar (not shown).

In Figure $7 \mathrm{D}(n=5)$ in $13.9 \pm 1.8 \mathrm{mM}\left[\mathrm{K}^{+}\right]_{\mathrm{o}}$, $3.9 \mathrm{mM} \mathrm{Ca}^{2+}$ markedly increased both rate and force and enhanced the effects of overdrive, including a shortening of the pause. Therefore, in Tyrode, high $\left[\mathrm{Ca}^{2+}\right]_{\mathrm{o}}$ increases force more than the (already high) rate and influences but little the pause. In high $\left[\mathrm{K}^{+}\right]_{\mathrm{o}}$, high $\left[\mathrm{Ca}^{2+}\right]_{\mathrm{o}}$ increases force and rate before, during and after drive, and shortens the pause.

\section{Nickel enhances overdrive suppression}

If overdrive excitation and overdrive suppression interact in determining the pause, then decreasing $\mathrm{Ca}^{2+}$ load by means of a $\mathrm{Ca}^{2+}$ channel blocker would be expected to enhance overdrive suppression.

In Figure 8A, in Tyrode solution, overdrive caused the usual changes in force and rate patterns. As shown in the trace underneath, $\mathrm{Ni}^{2+}$ reduced both force and rate. During overdrive, force increased more slowly than in the absence of $\mathrm{Ni}^{2+}$ (cf. grey areas), but by the end of drive force had increased substantially. The cessation of overdrive was followed by a longer pause and a larger first contraction than in control. The longer pause apparently contributed to subsequent stronger first beat, since force declined relatively quick to the low steady state. In the boxed inset, with respect to the pre-drive cycle length (marked by the joined gray lines), drive prolonged the pause much more in the presence of $\mathrm{Ni}^{2+}$. 


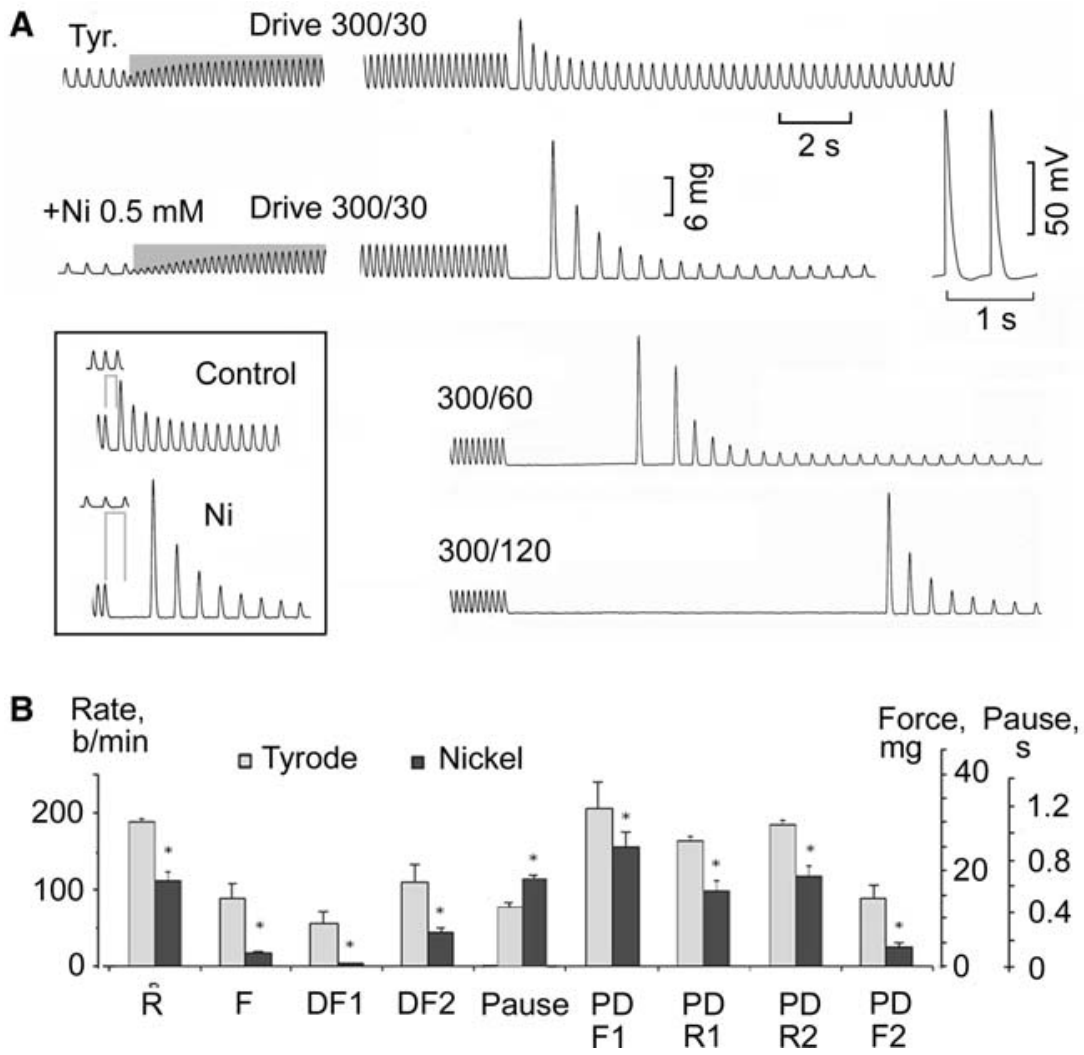

Figure 8. Effects of nickel on rate and force overdrive patterns. In A, the top trace was recorded in Tyrode solution and the bottom trace after adding $0.5 \mathrm{mM}$ nickel. The slower growth of force during drive is emphasized by the grey areas. In the boxed inset, the joined vertical grey lines label the cycle length in control and in the presence of $\mathrm{Ni}^{2+}$. In $\mathrm{B}$, the average values in the Tyrode and in $\mathrm{Ni}^{2+}$ solutions are shown.

In the presence of $\mathrm{Ni}^{2+}$, the ratio overdrive/ spontaneous rate was greater than in control since the basal rate was less. Still, prolonging the drive from 30 to 60 and to $120 \mathrm{~s}$ (bottom two A traces) led to much longer pauses, which were dependent on drive duration and not on the overdrive/ spontaneous rate unchanged ratio.

In Figure 8B, in Tyrode solution $(n=8)$ $0.5 \mathrm{mM} \mathrm{Ni}^{2+}$ decreased rate and force prior, during and after $30 \mathrm{~s}$ overdrive and increased the pause. In high $\left[\mathrm{K}^{+}\right]_{\mathrm{o}}(n=4), 0.35 \mathrm{mM} \mathrm{Ni}^{2+}$ also decreased the rate $\left(\mathrm{R}-15 \%, \mathrm{PDR}_{1}-8.9 \%\right.$, and $\left.\mathrm{PDR}_{2}-1.1 \%\right)$, decreased force $\left(\mathrm{F}-25.7 \% *, \mathrm{DF}_{2}\right.$ $\left.-28.7 \%, \mathrm{PDF}_{1}-44.3 \% *, \mathrm{PDF}_{2}-25.1 \% *\right)$, and increased the pause $(+36.0 \%)$. Therefore, $\mathrm{Ni}^{2+}$ has similar effects in high $\left[\mathrm{K}^{+}\right]_{\mathrm{o}}$. Overall, $\mathrm{Ni}^{2+}$ enhances overdrive suppression while decreasing rate and force.

\section{Effects of barium in Tyrode solution} and high $\left[K^{+}\right]_{o}$

Both diastolic depolarization and diastolic voltage oscillations play a role in SAN discharge [20]. $\mathrm{Ba}^{2+}$ increases $I_{\mathrm{Ca}}$, but decreases the delayed rectifier current $I_{\mathrm{K}}$ [27], which is the SAN dominant pacemaker current [28]. Therefore, $\mathrm{Ba}^{2+}$ may provide information as to the relative importance of $\mathrm{Ca}^{2+}$ load versus that of diastolic depolarization on drive-related rate and force patterns in Tyrode solution and high $\left[\mathrm{K}^{+}\right]_{\mathrm{o}}$.

In Figure 9A, in Tyrode solution $\mathrm{Ba}^{2+}$ increased force prior, during and after overdrive whereas it decreased the rate and increased the pause (see boxed inset). In Figure 9B $(n=11)$, in Tyrode solution, $0.64 \pm 0.1 \mathrm{mM} \mathrm{Ba}^{2+}$ decreased the rate and increased the pause as well as force $(\mathrm{R}-30.7 \%$, 


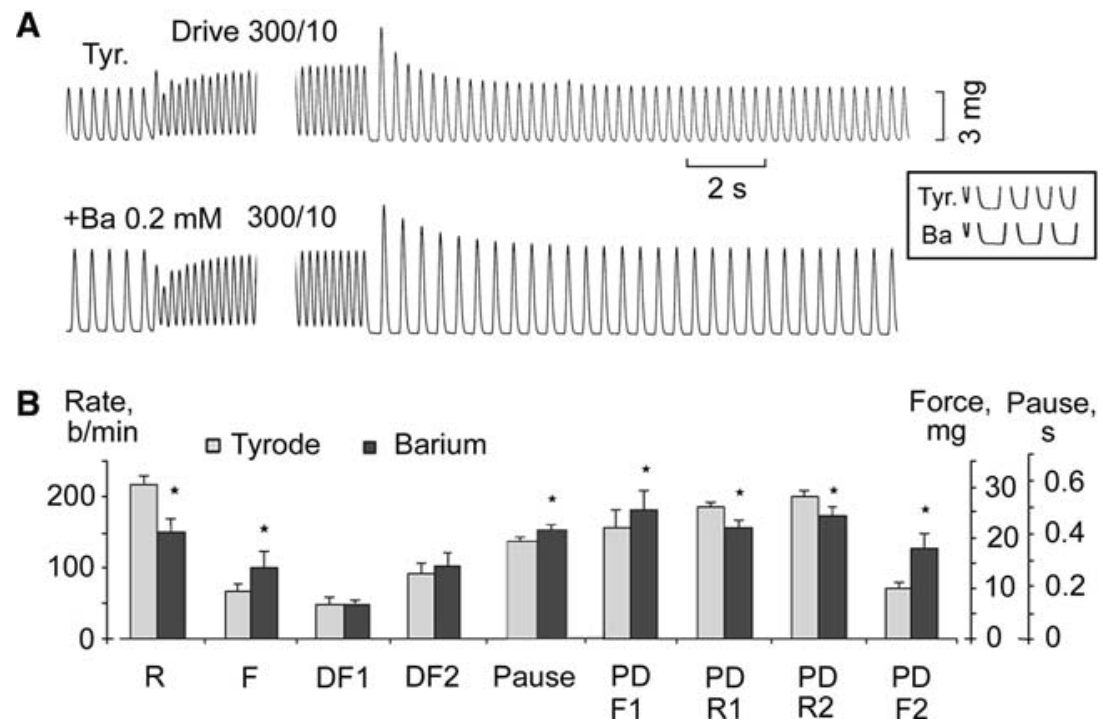

Figure 9. Effects of barium on rate and force patterns of overdrive. In A, overdrive was carried out in Tyrode solution (top trace) and after adding $0.2 \mathrm{mM} \mathrm{Ba}^{2+}$ (bottom trace). In $\mathrm{B}$, the average values in Tyrode and in $\mathrm{Ba}^{2+}$ solutions are shown.

$\mathrm{F}+54.3 \%, \mathrm{DF}_{2}+8.5 \%$, pause $+12.2 \%, \mathrm{PDF}_{1}$ $+15.4 \%, \mathrm{PDR}_{1}-15.2 \%, \mathrm{PDR}_{2}-14.1 \%$ and $\mathrm{PDF}_{2}$ $+88.7 \%)$. In high $\left[\mathrm{K}^{+}\right]_{\mathrm{o}}(n=4), 0.15 \pm 0.01 \mathrm{mM}$ $\mathrm{Ba}^{2+}$ had little effect on rate, increased force and shortened the pause $\left(\mathrm{R}+3.3 \%, \mathrm{~F}+23.9 \%, \mathrm{DF}_{1}\right.$ $-28.5 \%, \mathrm{DF}_{2}+32.4 \% *$, pause $-9.5 \%, \mathrm{PDF}_{1}$ $+27.0 \%, \mathrm{PDR}_{1}+30.0 \%, \mathrm{PDR}_{2}-0.3 \%$, and $\left.\mathrm{PDF}_{2}+45.4 \% *\right)$. Thus, while generally force and rate change in the same direction, the change can be dissociated by $\mathrm{Ba}^{2+}$.

\section{Electrical and mechanical events associated with overdrive and $\mathrm{Na}^{+}$channel blockers}

In high $\left[\mathrm{K}^{+}\right]_{\mathrm{o}}$, overdrive increases the diastolic oscillatory potentials [20]. The relation between changes in diastolic potentials and in force with overdrive is shown in Figure 10 in high $\left[\mathrm{K}^{+}\right]_{\mathrm{o}}$.

Before drive (Contr.), the distinct inflection during diastolic depolarization is typically due to a superimposed $\mathrm{V}_{\text {os }}$ (diamond in $\mathrm{A}$ and arrow in $\mathrm{C}$ ). In Figure 10A, after the $5 \mathrm{~s}$ overdrive, several changes are apparent. During the pause, diastolic depolarization no longer shows $\mathrm{V}_{\mathrm{os}}$, (see top traces in boxed inset $a$ ). After the pause, both force and $\mathrm{V}_{\text {os }}$ (cf. the grey areas in the traces labeled "Contr." and "5 s" in boxed inset b) increased above control. The steeper and larger $\mathrm{V}_{\text {os }}$ was responsible for increase in the late post-drive rate above control rate. The subsequent return of $\mathrm{V}_{\text {os }}$ toward control patterns was associated with a gradual subsiding of the rate toward the pre-drive value.

When overdrive duration was increased to $10 \mathrm{~s}$ (Figure 10B) and $30 \mathrm{~s}$ (Figure 10C), the pause became shorter (as emphasized by the grey vertical line in boxed inset $a$ ). The slope and size of $\mathrm{V}_{\mathrm{os}}$ increased further (see " $10 \mathrm{~s}$ " trace, boxed inset $b$ ) and then $\mathrm{V}_{\text {os }}$ became fused with $\mathrm{ThV}_{\text {os }}$ in a $\mathrm{U}$ shaped DD ("30 s" trace, boxed inset $b$ ). The growth of $\mathrm{V}_{\text {os }}$ is shown by the superimposed traces in the same inset (arrow). Thus, the pause involves a less steep DD and the acceleration involves an increase in slope and amplitude of $\mathrm{V}_{\text {os }}$ associated with an increase in force. The increase in $\mathrm{V}_{\text {os }}$ and force was greater with the longer drives.

Since norepinephrine increases $\mathrm{Ca}^{2+}$ load, the increase in $\mathrm{V}_{\text {os }}$ could be due to the release of NE by the electrical stimuli. To test this possibility, overdrive was carried out also in the presence of blockers of the fast $\mathrm{Na}^{+}$channels (lidocaine [29] and tetrodotoxin [30]). In Figure 11A, in high $\left[\mathrm{K}^{+}\right]_{\mathrm{o}}, \mathrm{V}_{\text {os }}$ was superimposed on DD (dot) which was absent during the pause (square, see superimposed control traces and grey area in boxed inset a). After the pause, slope and size of $\mathrm{V}_{\text {os }}$ increased until a U-shaped DD developed and $\mathrm{V}_{\text {os }}$ was no longer visible (see traces labeled with an asterisk and superimposed in the boxed inset $b$ under Cont.). At the same time, both rate and force were 


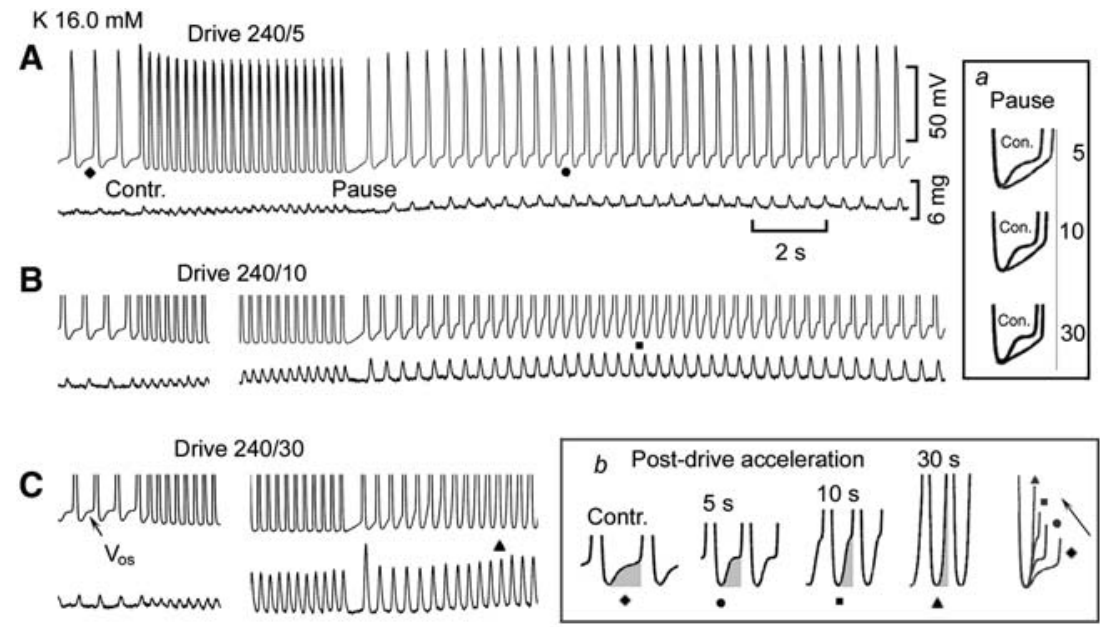

Figure 10. Effects of overdrives of different durations on diastolic potentials and force. The duration of the 240 drives was $5 \mathrm{~s}$ in $\mathrm{A}, 10 \mathrm{~s}$ in $\mathrm{B}$ and $30 \mathrm{~s}$ in $\mathrm{C}$. In the boxed inset $a$, diastolic depolarization in control (Con.) has been superimposed on that during the pause (the vertical grey line emphasizes the shortening of the pause). In the boxed inset $b$, the grey areas emphasize the growth of the slope and magnitude of $\mathrm{V}_{\text {os }}$ after the longer drives: the same symbols identify the same trace within and without the boxed inset. The arrow points to the successive changes in DD.

greater than prior to drive. The last A panel shows the reappearance of $\mathrm{V}_{\mathrm{os}}$, as rate and force returned toward pre-drive values.

In Figure 11B, lidocaine had decreased force to the baseline and abolished $\mathrm{V}_{\mathrm{os}}$ (triangle). Overdrive did not increase force above the baseline and induced a small pause (bottom traces in boxed inset a). After the pause, slope and size of DD increased with the appearance of a faint $\mathrm{V}_{\text {os }}$ (see middle trace in the boxed $b$ inset under Lido.) and this was associated with an increase in rate.

Tetrodotoxin was also tested since it blocks nerve action potentials in the nanomolar range [30], decreases intracellular $\mathrm{Na}^{+}$activity as well as force (see [31, 32]), and decreases $\mathrm{V}_{\text {os }}$ and $\mathrm{ThV}_{\mathrm{os}}$ [33]. In the boxed inset $c$, in a SAN superfused in high $\left[\mathrm{K}^{+}\right]_{\mathrm{o}}$, the bottom part of the last two driven action potentials and the subsequent pause are shown. Prior to overdrive, $\mathrm{V}_{\mathrm{os}}$ was not visible either in control or in the presence of TTX as apparently it was fused with DD. But during the pause, in the presence of TTX small $\mathrm{V}_{\text {os }}$ appeared (dots) as they missed the threshold.

Thus, the pause appears associated with a temporary reduction in the slope of DD which is later followed by an enhanced $V_{\text {os }}$ and an increase in rate and force. In the presence of lidocaine and TTX, the less steep DD during the pause also tends to re-increase after the drive, but less than in control as the diastolic potentials are smaller.

In Figure 11C, in Tyrode solution $(n=9)$, lidocaine $(100 \mu \mathrm{M})$ decreased rate and force and prolonged the pause $(+184.2 \%)$. In high $\left[\mathrm{K}^{+}\right]_{\mathrm{o}}$ $(11.5 \pm 1.2 \mathrm{mM}, n=4)$, lidocaine slowed the SAN in two experiments and stopped it in the other two. In $n=2$, overdrive for $60 \mathrm{~s}$ increased the force by $993.3 \%$ and induced overdrive excitation. In Figure 11D, in Tyrode solution $(n=7)$, TTX $(2.08 \mu \mathrm{M})$ also decreased rate and force, and prolonged the pause, as lidocaine did.

\section{Discussion}

Our results lead us to conclude that: (1) the excitatory effects of overdrive (increase in force and rate, shorter pause or induction of spontaneous discharge) are enhanced when $\mathrm{Ca}^{2+}$ loading prevails at less negative potentials; (2) less negative diastolic potentials appear to decrease the rate of $\mathrm{Ca}^{2+}$ extrusion, since force increases more during overdrive and the greater force and rate subside more slowly during recovery; (3) at less negative diastolic potentials, overdrive-induced increase in $\mathrm{Ca}^{2+}$ load leads to simultaneous increase in force and in the size and slope of diastolic potential (and therefore in rate of 


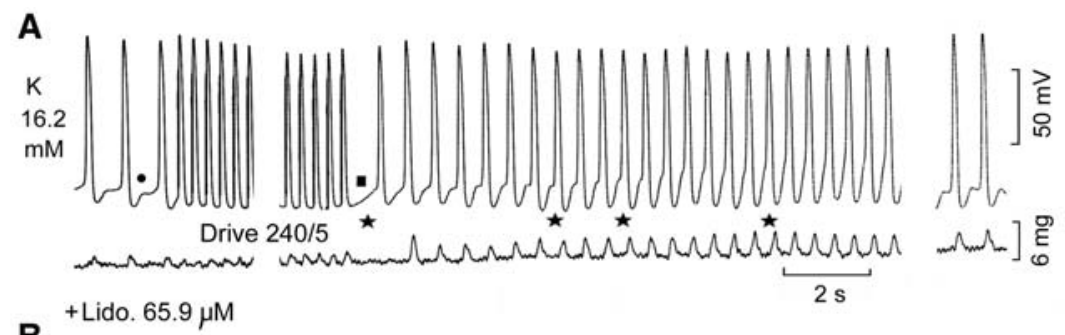

B
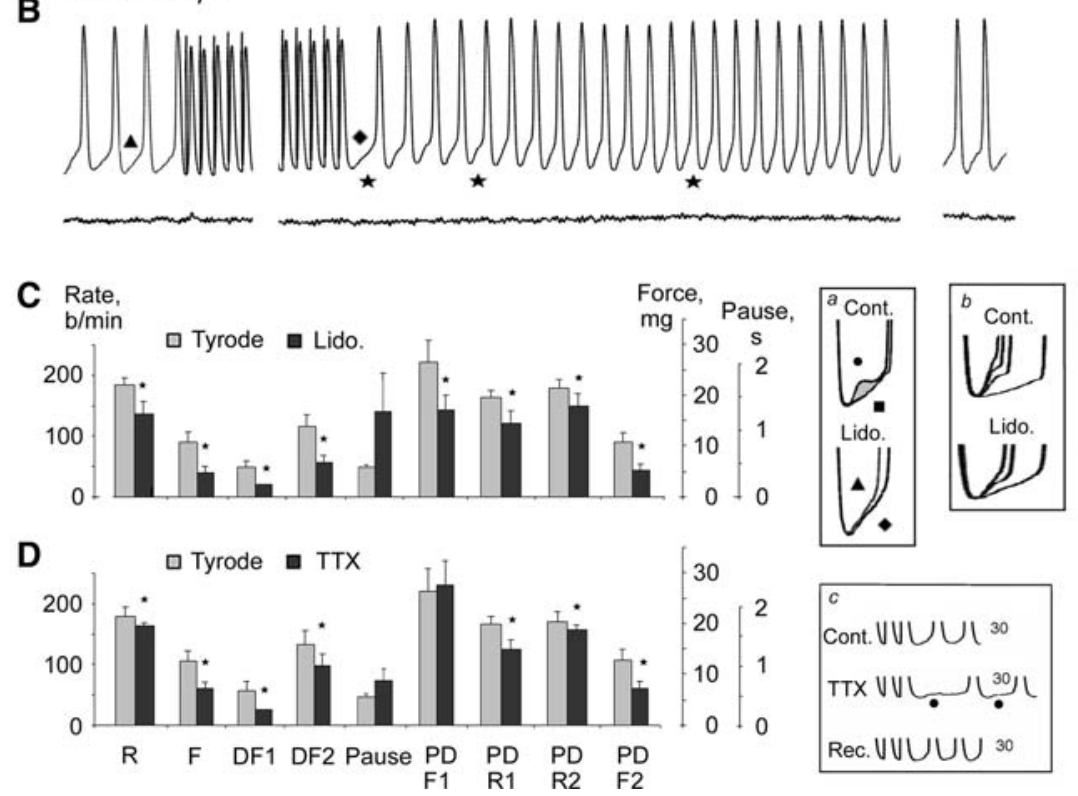

Figure 11. Effects of lidocaine and TTX on rate and force overdrive patterns. The action potentials and force were recorded in $16.2 \mathrm{mM}\left[\mathrm{K}^{+}\right]_{\mathrm{o}}$ in the absence (panel A) and the presence (panel B) of $65.9 \mu \mathrm{M}$ lidocaine. In boxed inset $a$, the diastolic potential before overdrive has been superimposed on that during the pause in control (Contr.) and in the presence of lidocaine (Lido.): the same symbols identify the same trace within and without the boxed inset. The diastolic potentials marked by asterisks have been superimposed in boxed inset $b$ in control (Contr.) and in the presence of lidocaine (Lido.). In boxed inset $c$, the lower part of the last two driven APs and of the first two spontaneous APs after drive are shown. The dots emphasize subthreshold diastolic oscillations. The average results of overdrive on rate and force patterns are shown in $\mathrm{C}$ for lidocaine and in $\mathrm{D}$ for tetrodotoxin.

discharge); (4) conversely, the inhibitory effects of overdrive (decrease in force and rate, longer pause) are enhanced when the $\mathrm{Ca}^{2+}$ load is decreased by $\mathrm{Ni}^{2+}$, lidocaine and TTX; (5) the effects of $\mathrm{Ca}^{2+}$ loading on force can be separated from those on rate by $\mathrm{Ba}^{2+}$ which increase $I_{\mathrm{Ca}}$ but decreases the pacemaker current; and (6) the unmasking of overdrive excitation and overdrive suppression under suitable conditions suggests that in Tyrode solution the pause is little affected by longer or faster drive, because of the interaction between the simultaneous increase in the excitatory (dominant pacemakers) and inhibitory (subsidiary pacemakers) effects of overdrive.

\section{Overdrive, increased calcium load and force}

It is generally agreed that force development is a function of $\mathrm{Ca}^{2+}$ loading [see 5, 34]: indeed, an increase in rate increases cellular $\mathrm{Ca}^{2+}$ in all cardiac tissues including the SAN (e.g., [3-6]. Also, overdrive-induced force patterns in SAN are similar to those in other cardiac tissues (e.g., [2, 7]). During longer or faster overdrives, contraction increases as a function of the number of driven APs, since during the AP $\mathrm{Ca}^{2+}$ enters the cells through the more often activated $I_{C a}$ and the reverse NCX. Furthermore, during overdrive a shorter diastole decreases the time available for $\mathrm{Ca}^{2+}$ extrusion from the cell by the $\mathrm{Na}-\mathrm{Ca}$ exchange and this too 
would contribute to the gradual increase in force. Thus, force $\left(\mathrm{DF}_{2}\right)$ increases as a function of the duration of overdrive (Figure 1B) and even more so in high $\left[\mathrm{K}^{+}\right]_{\mathrm{o}}$ (Figure 2B).

A sudden change in duration of diastole is a variable that appears to influence force of the next beat. One likely mechanism is that during diastole cytoplasmic $\mathrm{Ca}^{2+}$ is taken up by the sarcotubular network and transferred to the subsarcolemmal cisternae [35]. Therefore, after a sudden shortening of diastole, less $\mathrm{Ca}^{2+}$ is collected in and can be released from the SR cisternae by the next AP: the consequent contraction is weaker, as it happens with the first beat of drive ( $\mathrm{DF}_{1}$, Figures 1B, 2B). Conversely, a sudden lengthening of diastole (e.g., during the pause) allows more time for $\mathrm{Ca}^{2+}$ re-accumulation into the subsarcolemmal cisternae [35] and this would contribute to the stronger contraction of the first beat after the pause $\left(\mathrm{PDF}_{1}\right.$, Figures 1B, 2B). However, the predominant role of $\mathrm{Ca}^{2+}$ loading by overdrive on force development is shown by the fact that force increases during overdrive in the presence of a diastole of constant duration and $\mathrm{PDF}_{1}$ increases progressively with longer drives even if the pause either changes very little (Tyrode solution) or actually shortens (high $\left[\mathrm{K}^{+}\right]_{\mathrm{o}}$ ) (Figures 1B, 2B).

The relationship between $\mathrm{Ca}^{2+}$ loading and force is emphasized by the fact that high $\left[\mathrm{Ca}^{2+}\right]_{0}$ (Figure 7) and $\mathrm{Ba}^{2+}$ (Figure 9) increase force whereas $\mathrm{Ni}^{2+}$ decreases it (Figure 8). Also, high $\left[\mathrm{K}^{+}\right]_{\mathrm{o}}$ decreases $I_{\mathrm{Ca}}$ [24] and decreases force (compare control force in Tyrode solution in Figure $1 \mathrm{~B}$ with that in high $\left[\mathrm{K}^{+}\right]_{\mathrm{o}}$ in Figure 2B). An increase or decrease of $\mathrm{Ca}^{2+}$ entry acts in so far it changes intracellular $\mathrm{Ca}^{2+}$. Thus, lidocaine (Figure 11C) and TTX (Figure 11D) reduce force even more than the rate. In this respect, TTX and lidocaine act like high $\left[\mathrm{K}^{+}\right]_{0}$ does, probably through a similar mechanism (a decrease in $a_{\mathrm{Na}}^{\mathrm{i}}$ and therefore in $\left.\left[\mathrm{Ca}^{2+}\right]_{\mathrm{i}}\right)$. Thus, in Purkinje fibers, TTX decreases $a_{\mathrm{Na}}^{\mathrm{i}}$ as well as force [31, 32]. Also, TTX markedly decreases $\mathrm{V}_{\text {os }}$ in SAN perfused in high $\left[\mathrm{K}^{+}\right]_{\mathrm{o}}[33]$ and, in the present experiments, reduced force and DD slope by decreasing the size of diastolic oscillations.

The findings in high $\left[\mathrm{K}^{+}\right]_{\mathrm{o}}$ show that an additional mechanism (peculiar to the slow responses) contributes to increase intracellular $\mathrm{Ca}^{2+}$ by overdrive. In high $\left[\mathrm{K}^{+}\right]_{\mathrm{o}}$, longer overdrives percentage-wise increase force more and the great- er force returns more slowly toward pre-drive values (Figures 2-6) compared to Tyrode solution (Figures 1,5). That a reduced rate of extrusion of $\mathrm{Ca}^{2+}$ contributes to the increase in force in high $\left[\mathrm{K}^{+}\right]_{\mathrm{o}}$ is indicated by the fact: $(a)$ during recovery from overdrive, when the duration of diastole was kept constant and long enough for the full recovery of $I_{\mathrm{Ca}}$, the greater force took longer to recede, as expected from diminished rate of $\mathrm{Ca}^{2+}$ extrusion (Figure 3); (b) a $10 \mathrm{~s}$ pause was not sufficient to allow the extrusion of all the $\mathrm{Ca}^{2+}$ that entered during the previous $10 \mathrm{~s}$ drive, since the force kept on increasing with successive drives; and $(c)$ only after rather longer and repeated pauses did the overdrive force patterns revert to the original control value (Figure 4). The cumulative increment in force with intermittent overdrives and its slower subsiding in high $\left[\mathrm{K}^{+}\right]_{\mathrm{o}}$ (Figure 5B) are in sharp contrast with the findings in Tyrode solution (Figure 5A), since in Tyrode solution force changes little with successive drives and during recovery it subsided in $\leq 5 \mathrm{~s}$.

As for the mechanism by which $\mathrm{Ca}^{2+}$ extrusion might be less efficient in high $\left[\mathrm{K}^{+}\right]_{\mathrm{o}}$ with respect to Tyrode solution, one major difference is that in high $\left[\mathrm{K}^{+}\right]_{\mathrm{o}}$ the diastolic potential is less negative than in Tyrode solution [17-20]. Since the driving force for $\mathrm{Ca}^{2+}$ extrusion is the $\mathrm{Na}^{+}$electrochemical gradient [14], a reduction of such a gradient due to the less negative diastolic potential would be expected to reduce $\mathrm{Ca}^{2+}$ extrusion in the unit of time. This conclusion is supported by the fact that high $\mathrm{Cs}^{+}$(which also decreases the SAN diastolic potential [16]) affected overdrive force patterns similarly to high $\left[\mathrm{K}^{+}\right]_{\mathrm{o}}$.

Thus, the present findings indicate that with overdrive force development in the SAN is a function of $\mathrm{Ca}^{2+}$ load (more numerous APs in the unit of time during overdrive), the sudden changes in the duration of diastole (transfer of $\mathrm{Ca}^{2+}$ to the SR subsarcolemmal cisternae) and $\mathrm{Ca}^{2+}$ extrusion (reduced by a shorter diastole during overdrive and by a less negative diastolic potential). As for the hyperpolarization-activated $I_{\mathrm{f}}$ being increased by high $\left[\mathrm{K}^{+}\right]_{\mathrm{o}}$, it should be noted that high $\left[\mathrm{K}^{+}\right]_{\mathrm{o}}$ decreases the rate and (by decreasing the diastolic potential) would diminish the $I_{\mathrm{f}}$ activation. Overdrive would act similarly, since the $I_{\mathrm{f}}$ activation during the shorter diastole would be less. Further, $I_{\mathrm{f}}$ is not the dominant pacemaker current in the SAN [28]. 


\section{Calcium load and dominant discharge}

The results indicate that overdrive excitation predominates when $\mathrm{Ca}^{2+}$ load is greater either absolutely (overdrive, high $\left[\mathrm{Ca}^{2+}\right]_{\mathrm{o}}, \mathrm{Ba}^{2+}$, reduced extrusion of cellular $\mathrm{Ca}^{2}$ ) or relatively (lower $\mathrm{Na}^{+}$ load due to depolarization and inactivation of fast $\mathrm{Na}^{+}$channels). Overdrive excitation is thus characterized by a simultaneous increase in force and rate. This raises the question as to whether and how an increase in force might be linked to an increased in rate.

In this connection, a major finding is that in the SAN perfused in suitably high $\left[\mathrm{K}^{+}\right]_{\mathrm{o}}$ the depolarization changes the subsidiary fast APs into slow responses [16-20,36]. This on the one hand decreases the $\mathrm{Na}^{+}$load due to the inactivation of the fast $\mathrm{Na}^{+}$channel (slow responses instead of fast APs) and on the other enhances the $\mathrm{Ca}^{2+}$ load by overdrive (more slow responses and decreased rate of $\mathrm{Ca}^{2+}$ extrusion). If the behavior of the slow responses in high $\left[\mathrm{K}^{+}\right]_{\mathrm{o}}$ reflects that of dominant pacemakers (see below), the findings provide substantial insights in the operation of the SAN dominant pacemakers. This has to do with the presence of oscillatory potentials in the SAN [17-20].

In Tyrode solution, the U-shaped DD is usually ascribed to the pacemaker current (for the ionic species responsible for the dominant pacemaker current see [28]). However, when $\left[\mathrm{K}^{+}\right]_{\mathrm{o}}$ is gradually increased, DD misses the threshold and this unmasks two different diastolic oscillations [17-20, 33]. One is the oscillatory after-potential $\mathrm{V}_{\mathrm{os}}$, which is obligatorily superimposed on early DD $\left(\mathrm{DD}_{1}\right)$ since it requires a previous $\mathrm{AP}$ to be generated (see [37]). The other is the oscillatory pre-potential $\mathrm{ThV}_{\text {os }}$ (the oscillatory potential near the threshold for the upstroke), which can occur at any time during diastole. Decreasing $\left[\mathrm{K}^{+}\right]_{\mathrm{o}}$ back to normal allows $\mathrm{ThV}_{\text {os }}$ to increase in size, initiate sooner during diastole and fuse with $\mathrm{V}_{\text {os }}$ : force at the same time increases. Eventually DD, $\mathrm{V}_{\text {os }}$ and $\mathrm{ThV}_{\mathrm{os}}$ become indistinguishable in the U-shaped DD [20].

$\mathrm{V}_{\text {os }}$ and $\mathrm{ThV}_{\text {os }}$ are $\mathrm{Ca}^{2+}$-dependent, in that both are augmented by interventions that increase cellular calcium (high $\left[\mathrm{Ca}^{2+}\right]_{\mathrm{o}}$, fast drive $[18,20]$, norepinephrine [26], slower $\mathrm{Ca}^{2+}$ extrusion) and decreased by interventions that decrease cellular calcium (low $\left[\mathrm{Ca}^{2+}\right]_{\mathrm{o}}, \mathrm{Ni}^{2+}$ [20] and TTX [33]).
The role of a less negative diastolic potential in reducing $\mathrm{Ca}^{2+}$ extrusion in high $\left[\mathrm{K}^{+}\right]_{0}$ would apply also to dominant pacemakers in Tyrode solution, since their diastolic potential is 20$30 \mathrm{mV}$ less negative than that of SAN subsidiary pacemakers $[19,20,26]$. That the extrusion of $\mathrm{Ca}^{2+}$ is more effective in Tyrode solution is suggested by the fact that during intermittent overdrives force decreased toward pre-drive value within $5 \mathrm{~s}$, thereby preventing a cumulative effect of repeated drives on force and rate. An overall more negative diastolic potential in Tyrode solution may play a role in the differences with high $\left[\mathrm{K}^{+}\right]_{\mathrm{o}}$.

In the present context, the evidence indicates that overdrive increases force and rate through the generally agreed [3-6] increase in cellular calcium. Furthermore, in high $\left[\mathrm{K}^{+}\right]_{\mathrm{o}}$ overdrive is shown to simultaneously increase the twitch and the size as well as slope of diastolic potential which then subside together during recovery (Figure 10). One mechanism linking the increase in $\mathrm{Ca}^{2+}$ load with a larger diastolic potential might be that in SAN cells the SR is sparse [38] and therefore easily $\mathrm{Ca}^{2+}$ overloaded. The obligatory role of $\mathrm{Ca}^{2+}$ load in overdrive excitation in high $\left[\mathrm{K}^{+}\right]_{\mathrm{o}}$ is indicated by the fact that short drives do not increase force above the pre-drive value and are followed by a longer (not a shorter) pause with respect to Tyrode solution (high $\left[\mathrm{K}^{+}\right]_{\mathrm{o}}$ decreases $I_{C a}[24]$ and force, Figure 2). Only longer drives increase force above control and are followed by a shorter pause as well as greater force and rate.

The implication of the present findings is that the SAN dominant pacemakers are not inhibited by an increase in rate (intrinsic or extrinsic) in virtue of the APs being slow responses (prevalent $\mathrm{Ca}^{2+}$ loading). The increased $\mathrm{Ca}^{2+}$ load and slower $\mathrm{Ca}^{2+}$ extrusion insures that the $\mathrm{Ca}^{2+}$ overloaded SR releases more $\mathrm{Ca}^{2+}$ in diastole. The consequent enhancement of the diastolic potentials leads to overdrive excitation. Instead, overdrive suppresses the discharge of cat surgically separated SAN subsidiary pacemakers (see [8]), since the latter are fast responses (enhancement of the electrogenic $\mathrm{Na}^{+}$extrusion by overdrive) and their DD is too negative for $\mathrm{ThV}_{\text {os }}$ to be present [20]. In intact SAN, the reduced slope of DD of subsidiary pacemakers by $\mathrm{Na}^{+}$extrusion would electrotonically antagonize overdrive excitation of dominant pacemakers. 
It should be added that dominant pacemaker slow responses in Tyrode solution and those in suitably high $\left[\mathrm{K}^{+}\right]_{\mathrm{o}}$ have the same configuration and behave similarly. Thus, the slow responses of dominant pacemakers and those in high $\left[\mathrm{K}^{+}\right]_{\mathrm{o}}$ are suppressed by acetylcholine [39], enhanced by norepinephrine [26], increased by high and decreased by low $\left[\mathrm{Ca}^{2+}\right]_{0}$ [26], and are abolished by high $\mathrm{Ni}^{2+}[20]$.

\section{Overdrive excitation and diastolic potential}

The present results indicate that the prevalent $\mathrm{Ca}^{2+}$ loading and the less negative diastolic potential in the slow responses are essential for dominant pacemaker discharge and for overdrive excitation. These characteristics result in a contribution of $\mathrm{Ca}^{2+}$-dependent diastolic oscillations to the U-shaped DD (and therefore to fast discharge) and to the lack of frequency-dependent selfsuppression. In fact, the induction of excitation by overdrive in dominant pacemakers might be viewed as a protective mechanism against the simultaneous enhancement of overdrive suppression in SAN subsidiary pacemakers.

This functional organization of dominant pacemakers appears to center on the lack of expression of $I_{\mathrm{K} 1}$ channels (see [40]). The consequently reduced background $\mathrm{K}^{+}$current would result in: (1) a less negative diastolic potential; (2) the inactivation of $\mathrm{Na}^{+}$channels even if expressed; and (3) $\mathrm{a} \mathrm{Ca}^{2+}$-dependent slow response. The less negative diastolic potential would permit DD to enter the oscillatory zone (induction of $\mathrm{ThV}_{\mathrm{os}}$ ) and a less efficient $\mathrm{Ca}^{2+}$ extrusion $\left(\mathrm{Ca}^{2+}\right.$ overload of the SR and induction of $\mathrm{V}_{\mathrm{os}}$ ). The lack of $I_{\mathrm{K} 1}$ acts only insofar as it depolarizes the diastolic potential, since high $\left[\mathrm{K}^{+}\right]_{\mathrm{o}}$ (which increases $I_{\mathrm{K} 1}$ ) also induces the slow responses through a depolarization (less negative $E_{\mathrm{K}}$ ).

\section{Clinical implications}

Under normal conditions, SAN dominant pacemakers are not overdriven, but the mechanisms related to overdrive are operating all the time, since an increase in rate loads dominant pacemaker cells with $\mathrm{Ca}^{2+}$. Thus, discharge of dominant pacemaker cells tend to sustain their spontaneous activity, instead of being self-inhibitory like for fast-response subsidiary pacemakers.
Arrhthymias (such atrial tachycardias, flutter and fibrillation) could overdrive the SAN at rates as fast as those tested here. The peculiar organization of the ionic exchange in dominant pacemaker cells tends to reduce overdrive suppression that would follow the stoppage of these tachycardias. This means that the dominant SAN pacemakers on the one hand inhibit subsidiary pacemakers in virtue of their fast rate and on the other they are protected from frequency-dependent suppression by the relation between $\mathrm{Ca}^{2+}$ load and dominant discharge (enhancement of oscillatory potentials).

Also, the results provide essential insights on the effects of hyperkalemia and on the therapeutic action of $\mathrm{Ca}^{2+}$ administration in patients. The SAN is particularly resistant to an increased $\mathrm{K}^{+}$ plasma level and this is due in part to sympathetic innervation [41] and in part to the fact that (while high $\left[\mathrm{K}^{+}\right]_{\mathrm{o}}$ increases $g_{\mathrm{K} 1}$ ) it has little effects on the dominant pacemaker current $I_{\mathrm{K}}$ [24]. The present results indicate that the therapeutic effect of $\mathrm{Ca}^{2+}$ administration in hyperkalemia might be related to the fact that an increased $\mathrm{Ca}^{2+}$ loading of SAN depolarized in high $\left[\mathrm{K}^{+}\right]$fosters spontaneous discharge (Fig. 7B).

\section{Acknowledgements}

This work was supported by a grant from the National Institutes of Health (HL56092). Adam Graziani was supported by a Chandler McCuskey Brooks Research Award. We kindly thank Jeremy Weedon Ph.D., Senior Statistician at SUNY Downstate Scientific Computing Center, for his expert help with the evaluation of the statistical significance of the changes in several parameters.

\section{References}

1. Cohen C.J., Fozzard H.A. and Sheu S.-S., Increase in intracellular sodium ion activity during stimulation in mammalian cardiac muscle. Circ. Res. 50: 651-662, 1982.

2. Abete $\mathrm{P}$. and Vassalle M., Relation among $\mathrm{Na}^{+}-\mathrm{K}^{+}$pump, $\mathrm{Na}^{+}$activity and force in strophanthidin inotropy in sheep cardiac Purkinje fibres. J. Physiol. (London) 404: 275-299, 1988.

3. Langer G.A., Heart: excitation-contraction coupling. Ann. Rev. Pharmacol. 35: 55-86, 1973.

4. Lado M.G., Sheu S.-S. and Fozzard H.A., Changes in intracellular $\mathrm{Ca}^{2+}$ activity with stimulation in sheep cardiac Purkinje strands. Am. J. Physiol. 243: H133-H137, 1982. 
5. Eisner D.A., Diaz M.E., Li Y., O'Neill S.C. and Trafford A.W., Stability and instability of regulation of intracellular calcium. Exp. Physiol. 90: 3-12, 2005.

6. Vinogradova T.M., Zhou Y.Y., Maltsev V., Lyashkov A., Stern M. and Lakatta E.G., Rhythmic ryanodine receptor $\mathrm{Ca}^{2+}$ releases during diastolic depolarization of sinoatrial pacemaker cells do not require membrane depolarization. Circ. Res. 94: 802-809, 2004.

7. Kotake H. and Vassalle M., Rate-force relationship and calcium overload in canine Purkinje fibers. J. Mol. Cell. Cardiol. 18: 1047-1066, 1986.

8. Lu H.-H., Lange G. and Brooks C.McC., Factors controlling pacemaker actions in cells of the sinoatrial node. Circ. Res. 17: 460-471, 1965.

9. Lange G., Action of driving stimuli from intrinsic and intrinsic sources on in situ cardiac pacemaker tissues. Circ. Res. 17: 449-459, 1965.

10. Vassalle M., Electrogenic suppression of automaticity in sheep and dog Purkinje fibers. Circ. Res. 27: 361-377, 1970.

11. Brooks C.McC. and Lu H.-H., The Sinoatrial Pacemaker of the Heart. Thomas, Springfield, IL, 1972.

12. Lipsius S.L. and Vassalle M., Characterization of a twocomponent upstroke in the sinus node subsidiary pacemakers. In: Bonke FIM (Ed), The Sinus Node, Structure, Function and Clinical Relevance. Nijhoff BV Publishers, The Hague, 1978, pp. 233-244.

13. Opthof T., de Jonge B., MacKaay A.J.C., Bleeker W.K., Masson-Pévet M., Jongsma H.J. and Bouman L.N., Functional and morphological organization of the guineapig sinoatrial node compared with the rabbit sinoatrial node. J. Mol. Cell. Cardiol. 17: 549-564, 1985.

14. Mullins L.J., The generation of electric currents in cardiac fibers by $\mathrm{Na} / \mathrm{Ca}$ exchange. Am. J. Physiol. 236: C103-C110, 1979.

15. Thomas R.C., Electrophysiology of the sodium pump on a snail neuron. In: Slayman C.L. (Ed), Electrogenic Ion Pumps. Academic Press, New York, 1982, pp. 3-16.

16. Sohn H.G. and Vassalle M., Cesium effects on dual pacemaker mechanisms in guinea pig sinoatrial node. J. Mol. Cell. Cardiol. 27: 563-577, 1995.

17. Kim E.M., Choy Y. and Vassalle M., Mechanisms of suppression and initiation of pacemaker activity in guinea pig sino-atrial node superfused in high $\left[\mathrm{K}^{+}\right]_{\mathrm{o}}$. J. Mol. Cell. Cardiol. 29: 1433-1445, 1997.

18. Choy Y., Kim E.M. and Vassalle M, Overdrive excitation in the guinea pig sino-atrial node superfused in high $\left[\mathrm{K}^{+}\right]_{\mathrm{o}}$. J. Biomed. Sci. 4: 179-191, 1997.

19. Zhang H. and Vassalle M., Role of dual pacemaker mechanisms in sino-atrial node discharge. J. Biomed. Sci. 7: 100-113, 2000.

20. Nett M. and Vassalle M., Obligatory role of diastolic voltage oscillations in sino-atrial node discharge. J. Mol. Cell. Cardiol. 35: 1257-1276, 2003.

21. Vassalle M. and Carpentier R., Overdrive excitation: the initiation of spontaneous activity in Purkinje fibers following a fast drive in the presence of norepinephrine. Pflügers Arch. 332: 198-205, 1972.
22. Anderson R.H., The disposition, morphology and innervation of the cardiac specialized tissue in the guinea-pig. J. Anat. 111: 453-468, 1972.

23. Page E.B., Ordered hypotheses for multiple treatments: a significance test for linear ranks. J. Am. Statist. Ass. 58: 216-230, 1963.

24. Noma A., Mechanisms underlying cessation of rabbit sinoatrial node pacemaker activity in high potassium solutions. Jap. J. Physiol. 26: 619-630, 1976.

25. Shen J.-B. and Vassalle M., On the mechanism of cesiuminduced voltage and current tails in single ventricular myocytes. J. Biomed. Sci. 6: 161-175, 1999.

26. Zhang H. and Vassalle M., On the mechanisms of adrenergic control of the sino-atrial node discharge. J. Biomed. Sci. 10: 179-192, 2003.

27. Osterrieder W., Yang Q.F. and Trautwein W., Effects of barium on the membrane currents in the rabbit SA node. Pflügers Arch. 394: 78-84, 1982.

28. Zhang H. and Vassalle M., Role of $I_{K}$ and $I_{f}$ in the pacemaker mechanisms of sino-atrial node myocytes. Can. J. Physiol. Pharmacol. 79: 963-976, 2001.

29. Bean B.P., Cohen C.J. and Tsien R.W., Lidocaine block of cardiac sodium channel. J. Gen. Physiol. 81: 613-642, 1983.

30. Kao C.Y., Tetrodotoxin, saxitoxin and their significance in the study of excitation phenomena. Pharmacol. Rev. 18: 997-1049, 1966

31. Vassalle M. and Lee C.O., The relationship among intracellular sodium activity, calcium, and strophanthidin inotropy in canine cardiac Purkinje fibers. J. Gen. Physiol. 83: 287-307, 1984

32. Abete P. and Vassalle M., Strophanthidin and force regulation by intracellular sodium activity in cardiac Purkinje fibers. Eur. J. Pharmacol. 141: 51-65, 1987.

33. Catanzaro J.N., Nett M.P, Rota M. and Vassalle M. On the mechanisms underlying diastolic voltage oscillations in the sino-atrial node. J. Electrocardiol. 2006 (in press).

34. Fabiato A., Two kinds of calcium-induced release of calcium from the sarcoplasmic reticulum of skinned cardiac cells. Adv. Exp. Med. Biol. 311: 245-262, 1992.

35. Katz A.M., Physiology of the Heart. Lippincott Williams and Wilkins, Philadelphia, 2006, pp. 299-303.

36. Lipsius S.L. and Vassalle M., Dual excitatory channels in the sinus node. J. Mol. Cell. Cardiol. 10: 753-767, 1978.

37. Vassalle M. and Mugelli A., An oscillatory current in sheep cardiac Purkinje fibers. Circ. Res. 48: 618-631, 1981.

38. Masson-Pévet M., Bleeker W.K., Mackaay A.J.C., Gros D. and Bouman L.N., Ultrastructural and functional aspects of the rabbit sinoatrial node. In: Bonke FIM (Ed), The Sinus Node: Structure, Function and Clinical Relevance. Martinus Nijhoff Publisher, The Hague, 1978, pp. 195-211.

39. Vassalle M. and Zhang H., On the mechanisms of cholinergic control of the sino-atrial node discharge. J. Cardiovasc. Pharmacol. 37: 173-186, 2001.

40. Irisawa H., Brown H.F. and Giles W., Cardiac pacemaking in the sinoatrial node. Physiol. Rev. 73: 197-227, 1993.

41. Vassalle M., Greineder J.K. and Stuckey J.H., Role of the sympathetic nervous system in the sinus node resistance to high potassium. Circ. Res. 32: 348-354, 1973. 